\title{
WIND PRESSURES ON STRUCTURES
}

\author{
By Hugh L. Dryden and George C. Hill
}

ABSTRACT

There is a general feeling among engineers that the values of the pressure exerted by the wind commonly used in the design of engineering structures are too high. The experiments on which these values are based were carried out many years ago by relatively inaccurate methods and on models not resembling actual structures. The success of modern wind-tunnel methods in the field of aeronautics suggests their use for the determination of wind pressures on models of structures, and the present paper describes the results of some experiments on a model in the 10-foot wind tunnel of the Bureau of Standards.

The paper is divided into two parts, Part I being a general discussion of the subject. A general survey is given of the effects of a uniform and steady wind, and some discussion of the allowances to be made for the gustiness of the wind. Typical values of the coefficient of wind pressure are given for various types of models.

Part II describes experiments on a square base prism 241/4 inches high, the base being 8 inches square, at speeds up to 70 miles per hour. The pressure was measured at 70 stations on one face and 49 stations on the top for wind directions varying from $90^{\circ}$ to one face to $90^{\circ}$ to the opposite face by $15^{\circ}$ steps, the ground being represented by a fixed platform and in a second series of tests by the tunnel floor.

The chief conclusions of interest to structural engineers are as follows:

1. The greatest average pressure against the building occurs when the wind blows normal to a face and is equal to 1.5 times the velocity pressure; that is, 22 lbs./ft. ${ }^{2}$ for a true speed of 76 miles per hour (100 miles per hour indicated by a Weather Bureau Robinson type anemometer).

2. The average decrease in pressure over the roof is about 0.84 times the velocity pressure; that is, 12.4 lbs./ft. ${ }^{2}$ for a true speed of 76 miles per hour.

3. The maximum moment about a vertical axis is equivalent to a horizontal displacement of the resultant force of 0.077 times the width of the building.

\section{CONTENTS}

Part I.-GENERAL DISCUSSION OF WIND PRESSURE DATA

I. Introduction

II. Wind pressure exerted by uniform and steady winds_... . . . . 700

III. Wind pressure in gusty winds

Part II.-DISTRIBUTION OF PRESSURE OVER A MODEL OF A TALL BUILDING

I. Introduction _..... 704

II. Apparatus

1. The model

2. The wind stream

3. Speed measurement

4. The pressure gauge 
III. General procedure

IV. Reduction of observations

V. Results

VI. Accuracy

VII. Discussion

\section{Part I.-GENERAL DISCUSSION OF WIND PRESSURE DATA}

\section{INTRODUCTION}

In the design of any engineering structure, such as a tall building, a bridge, a chimney, or a radio tower, provision must be made for the stresses produced by wind pressure. The available data regarding the forces exerted by the wind are very meager and are based entirely on experiments made at a time when experimental methods were in the early stages of development. The present status of the subject of stresses in structures due to wind pressure was stated very clearly by the building code committee of the Department of Commerce in a memorandum to Secretary Hoover, June 18, 1924, as follows:

The building code committee in its consideration of allowable live loads which should be assumed in designing buildings has been confronted with the fact that very little authentic information is available as to the amount, distribution, and duration of wind stresses in buildings. It is recognized that wind does at times produce stresses of considerable magnitude in buildings, and most municipal building codes make provision for them. However, the assumptions as to what the wind forces will do and how they may be expected to act differ considerably and are generally believed to increase construction costs unnecessarily. On the other hand, discussions received from numerous architects and engineers indicate that there is a tendency to reduce or disregard assumptions formerly in force, a tendency which needs investigation from the standpoint of public safety.

The same general ideas were expressed 30 years ago by Capt. W. H. Bixby, United States Army, in a paper reprinted in Engineering News, March 14, 1895, page 175, and quoted by Robins Fleming in his book Wind Pressure on Structures, published in 1915 by the Engineering News Co. It may seem strange to find the same acknowledgment of ignorance made after a period of 30 years, but so slow has been the development of our knowledge of the subject. Only great disasters, which are fortunately infrequent, focus attention on the subject and inspire a study of the problem. The historical development of formulas now used, beginning with the SmeatonRouse ${ }^{1}$ formula, $P=0.005 V^{2}$, is traced in detail in the article and book quoted, and the earlier article contains valuable abstracts of the work of many investigators.

One very important factor retarding the advance of our knowledge of wind pressure is the great complexity of the subject. When we

I J. Smeaton, Phil. Trans. Roy. Soc.; 1750. 
consider that the stresses due to wind pressure depend on the form of the structure, the size of the structure, the speed and direction of the wind, and on the location of surrounding structures; when we consider the rapid fluctuations in the speed and direction of the wind; and when we consider that there is no practical method by which the wind loads may be obtained from the stresses in particular members of a complicated structure, it is not amazing that progress has been slow. Engineers are not generally agreed on a method of analysis of this complex problem; in fact, many methods may be used and many types of experiments must be performed before it will be possible to compute closely the stresses produced by wind pressure.

In considering the problem in its broad and general aspects, it resolves itself into two distinct questions. First, what are the maximum loads produced by the wind, and how often do they occur? This is the problem of the meteorologist and the aerodynamical physicist. Second, what are the stresses in the various members of the structure resulting from these loads? This is a problem for the structural engineer, and no further mention will be made in this paper of this aspect of the problem except to call attention to the fact that various methods are in use which give very different results for any particular member of the structure. (Fleming's book.) We believe this division of the problem to be a vital one, for we see no hope of advance unless the wind loads are investigated rather than the wind stresses.

The loads produced by the wind depend on the wind speed and direction. Now, the wind does not blow with a uniform speed or in a constant direction. The wind normally consists of a series of gusts, the speed and direction of which vary within wide limits. Many engineers feel that these gusts are more or less local in character and that the mean speed over a large area at any one instant is equal to the mean speed over a long time at any one place. Other authorities ${ }^{2}$ oppose this view, and experimental evidence is not available to decide which is more nearly correct. The determination of the structure of the wind is a problem of the meteorologist, and the maximum ioads due to gusts of various types must eventually be investigated by the meteorologist and the aerodynamical physicist. At first, however, it seems to us that we must know as well as possible what takes place under conditions which may be unambiguously defined and controlled, namely, in a wind of uniform speed and direction. We believe that advance should be made from the simple to the complex. On examination it is found that even the phenomena in a uniform and steady wind are not especially simple.

In the second place, the loads produced by the wind depend on the form of the structure against which the wind is blowing. This

\footnotetext{
2 Proc. Inst. Civ. Eng. (London), 276, Pt. II, p. 3; 1922-23.
} 
is a matter which has only recently been understood. We know now that measurements on a flat plate do not give results applicable to the side of a building. There is no definite pressure corresponding to a given wind speed applicable to all types of abjects. Many of the old experiments must be discarded or supplemented because of this fact, their models being merely flat plates or disks. Many experiments are now available which enable a general survey of the effect of form variations, but many more measurements are needed on models resembling more closely actual structures. The recent experiments have been carried out largely in the artificial wind streams produced in wind tunnels, which have proved so useful in the development of aeronautics, and the success of wind-tunnel methods in that field promises similar results in the investigation of wind pressures on structures.

\section{WIND PRESSURE EXERTED BY UNIFORM AND STEADY WINDS}

The nature of the reaction between the wind and an obstacle to its progress is extremely complicated even in the case of a uniform and steady wind. Two characteristics are being more and more appreciated. First, the reaction consists of a surface distribution of pressure and the representation of the action by a single resultant force is only a convenient mathematical device. Second, when the air is at rest there is a distribution of pressure over the surface due to the normal atmospheric pressure. The effect of the motion of the air is a modification of this normal pressure, at some points an increase in pressure, at others a decrease in pressure. The magnitude of these changes is only a small percentage of the normal atmospheric pressure, and the words "suction" or "vacuum" as commonly used in this connection do not imply any large change in density or pressure. The condition indicated by these words is merely a decrease of the normal pressure by amounts which are usually less than 2 per cent of the normal pressure.

The maximum increase in pressure produced by the wind is equal to $1 / 2 \rho V^{2}$ where $\rho$ is the density of the air and $V$ the wind speed. This pressure, usually termed the velocity pressure or impact pressure, is indicated by a Pitot-static tube of standard design. Pitotstatic tubes of poor design usually indicate a higher pressure because of a failure to give the true static or reference pressure. Values of the velocity pressure for various wind speeds are given in Table 1 for an air density of $0.07651 \mathrm{lb} . / \mathrm{ft}^{3}{ }^{3}$ corresponding to $15^{\circ} \mathrm{C}$., 760 $\mathrm{mm} \mathrm{Hg}$. The first column of the table gives the wind speed as indicated by a standard United States Wtather Bureau 4-cup Robinson 
type anemometer. The second gives the true wind speed as determined by the correction formula used by the Weather Bureau. ${ }^{3}$

TABLE 1.-T Trecity pressure $v$. true and indicated wind speed

\begin{tabular}{|c|c|c|c|c|c|}
\hline $\begin{array}{l}\text { Speed indicated by U. S. } \\
\text { Weather Bureau 4-cup Rob- } \\
\text { inson anemometer (miles } \\
\text { per hour) }\end{array}$ & $\begin{array}{l}\text { True } \\
\text { wind } \\
\text { speed }\end{array}$ & $\begin{array}{l}\text { Velocity } \\
\text { pressure }\end{array}$ & $\begin{array}{l}\text { Speed indicated by U. S. } \\
\text { Weather Bureau 4-cup Rob- } \\
\text { inson anemometer (miles } \\
\text { per hour) }\end{array}$ & $\begin{array}{l}\text { True } \\
\text { wind } \\
\text { speed }\end{array}$ & $\begin{array}{l}\text { Velocity } \\
\text { pressure }\end{array}$ \\
\hline $\begin{array}{l}10 \\
20 \\
30 \\
40 \\
50 \\
60 \\
70 \\
80\end{array}$ & $\begin{array}{r}\text { Miles per } \\
\text { hour } \\
9.5^{8} \\
17.8 \\
25.7 \\
33.3 \\
40.7 \\
48.0 \\
55.2 \\
62.2\end{array}$ & $\begin{array}{r}\text { Lbs./ft. }{ }^{2} \\
0.23 \\
.81 \\
1.69 \\
2.84 \\
4.23 \\
5.89 \\
7.80 \\
9.90\end{array}$ & $\begin{array}{l}90-100 \\
110 \\
120 \\
130 \\
150\end{array}$ & $\begin{array}{r}\text { Miles per } \\
\text { hour } \\
69.2 \\
76.1 \\
82.9 \\
89.7 \\
96.4 \\
103.1 \\
109.7\end{array}$ & \begin{tabular}{|l} 
Lbs. Ift. 2 \\
12.25 \\
14.8 \\
17.6 \\
20.6 \\
23.8 \\
27.2 \\
30.8
\end{tabular} \\
\hline
\end{tabular}

Log true speed $=0.9012(\log$ indicated speed $)+0.079$

Velocity pressure in lbs./ft. ${ }^{2}=0.001189\left(V \times \frac{22}{15}\right)^{2}$ where $V$ is the true speed in miles per bour.

In aerodynamics it is convenient to express all observed pressure differences as ratios of the pressure difference to the velocity pressure. Although the maximum increase in pressure at any point is equal to the velocity pressure, pressure decreases of greater amount frequently occur and average wind pressures resulting from the surface distribution over an object are frequently greater than the velocity pressure. The advantage of expressing results in this form is that the ratios or coefficients, as they are called, are independent of the units used so long as the units are self-consistent.

Expressed in this way the average wind pressure on a square flat plate normal to the wind is 1.12 times the velocity pressure; on a rectangular plate normal to the wind with ends shielded to give two dimensional flow, 2 times the velocity pressure. The maximum coefficient observed for any type of object is 2 . The average pressure on a rectangular prism of proportions $1: 1: 5$ when the wind is normal to one of the 1 by 5 faces is about 1.6 times the velocity pressure.

The coefficient in the cases mentioned is very nearly independent of wind speed or of the scale of the model. In general, however, the coefficient depends to some degree on the Reynolds number $\frac{V L}{\nu}$, $V$ being the wind speed, $L$ a linear dimension of the model, and $\nu$ the kinematic viscosity of the air (viscosity divided by the density): For spheres and cylinders the variation is very great and certain critical regions of Reynolds number occur in which the coefficient decreases very rapidly. In these cases it is difficult to predict the average pressure on the full-scale structure from the model. Such

3 Trans. Am. Soc. Civ. Eng., 37, p. 288; June, 1897. Also U. S. Department of Agriculture, Weather Bureau, instrument division, circular D, Anemoxnetry, $3 \mathrm{~d}$ ed., p. 16-18, 
variations of the coefficient with the Reynolds number are ordinarily spoken of as "scale effects." The general nature of the characteristics of form giving rise to scale effects is fairly well understood, but an extended discussion can not be given here. In general, bodies with flat surfaces and sharp edges show no scale effect or small scale effects.

The distribution of pressure which gives rise to the average pressures mentioned above depends largely on the form of the object and the same average pressure may result from widely different distributions. On the windward surfaces we find pressure increases varying from a maximum equal to the velocity pressure to values equal to a small fraction of the velocity pressure and in some cases regions of decreased pressure as well. On the leeward surfaces we usually find the pressure decreased. Even in the case where the resultant average pressure shows little or no scale effect, isolated regions of small area may show marked scale effects. Many of these points will be illustrated in the second part of this paper.

\section{WIND PRESSURE IN GUSTY WINDS}

In applying the results of measurements in a uniform and steady wind to the estimation of the wind loads exerted by gusty winds the final loading adopted in any particular case depends on the wind speed selected, the coefficient, and the area; and the allowable stress due to the wind load depends, in addition, on the value adopted for the working stress in the material. Considering the last point first, the working stress used in designing for wind stresses is frequently increased by as much as 50 per cent, on the ground that the maximum stresses seldom occur. This procedure is one aspect of modern practice which Fleming describes as giving an intellectual assent to the theories of the textbook and ignoring them in actual practice. It would seem more logical to reduce the value of the wind speed against which provision is to be made.

The selection of the wind speed to be used is a problem of great difficulty. Shall the average speed over long periods or the highest speed over some short-time interval be used? Shall the maximum average speed ever observed be used? In some cases, such as telephone or power lines, it is cheaper to rebuild occasionally than to build a structure strong enough to withstand the maximum observed speed. In buildings or bridges the element of human safety enters and the consideration of cost should not be the primary one, yet many feel that it is impracticable in tornado regions to build strong enough to withstand the maximum wind speeds. In general, for structures extending over a large area, such as buildings or bridges of long span, radio towers, etc., the average speed over a few minutes as given in the ordinary records is usually believed to provide ample safety, although some authorities believe that maximum gust 
velocities should be used. For small structures, on the other hand, such as water tanks, signs, short flagpoles, etc., values approaching the maximum gust velocities should certainly be used.

The area involved is usually the area projected on a plane normal to the wind. However, in test records the area used is explicitly stated and the value of the coefficient is dependent on the method of computing the area. The principal difficulty arises in those cases where certain members are shielded, as in a bridge or radio tower. For the present no general rules can be given and experiments in this field will prove of great value.

The coefficient to be used depends on the form of the object. The following tabulation indicates the general range of values and our recommendations for certain types of structures on the basis of present aerodynamical knowledge. In all cases the area involved is the area projected on a plane normal to the wind.

\begin{tabular}{|c|c|c|}
\hline Model investigated & $\begin{array}{l}\text { Coeffi- } \\
\text { cient }\end{array}$ & Application \\
\hline $\begin{array}{l}\text { Rectangular flat plate of infinite length, normal to the wind.... } \\
\text { Rectangular prism, } 1: 1: 5,1: 5 \text { face normal to the wind } \\
\text { Cylinder, } 1 \text { by } 5 \text {, axis normal to the wind } \\
\text { Short cylinder, } 1 \text { by } 1 \text {, axis normal to the wind. } \\
\text { Square flat plate, normal to the wind }\end{array}$ & $\begin{array}{r}2.0 \\
1.6 \\
.8 \\
.7 \\
1.1\end{array}$ & $\begin{array}{l}\text { Radio towers, bridge girders } \\
\text { Tall buildings. } \\
\text { Chimneys, standpipes. } \\
\text { Water tanks. } \\
\text { Square signboard. }\end{array}$ \\
\hline
\end{tabular}

In many cases the failure of individual walls or of the roof must be considered. Here the pressure in the interior of the building is a very important factor, since the force on the wall or roof depends on the difference in pressure between that on the interior surface and that on the exterior surface. Studies of pressure distribution over various types of buildings and of the effects of air leakage must be completed before accurate statements can be made as to appropriate loads to be used.

In concluding this brief survey of the general subject of wind pressure on structures it is desired to set forth the general program with which the Bureau of Standards experiments are correlated. We believe that wind loads should be investigated rather than wind stresses and that we must know what takes place in a uniform wind under controlled conditions before we can hope to find out what happens in a gusty wind. A glance at some of the contour plots of the pressure distribution over a rectangular prism shown later in this paper will show that this knowledge must be available for the interpretation of pressures measured at a few points on the large structure. When this preliminary information has been obtained, work may be begun on a structure of simple type in an exposed location in the natural wind. The interference effects of other buildings and the effects of air leakage may be passed by for the present. The present paper, it is hoped, is the first of a series dealing with various phases of the subject of wind pressure.

$$
70336^{\circ}-26 \uparrow-2
$$




\section{Part II.-DISTRIBUTION OF PRESSURE OVER A MODEL OF A TALL BUILDING}

\section{INTRODUCTION}

The structure decided upon for the first experiments was a tall building, and the information sought for was the distribution of wind pressure over the surface of the building in a nearly uniform and steady wind blowing perpendicular to the axis of the building, but at various angles to the face. On this first model a very careful survey was made with stations close together in order that some guide might be available for the location of stations on future models. For many reasons it was felt desirable to use for this intensive study a geometrical shape, and in order to decrease to some extent the labor and time involved a square-base prism was selected. The range of wind direction which must be covered is then only $45^{\circ}$, since all other wind directions give distributions which can be obtained from considerations of the symmetry of the model.

\section{APPARATUS}

\section{THE MODEL}

Figure 1 is a photograph of the model on its mounting. The model proper is a hollow rectangular parallelopiped 8 by 8 by $241 / 4$ inches in external dimensions and is made of sheet brass one-quarter inch thick. In one face of the house 70 holes are drilled, 0.040 inch in diameter and extending halfway through the face. In the inner surface larger holes are drilled and tapped to make a connection to the small holes. By means of nipples screwed in the large holes a rubber tube connection may be made to the pressure gauge. The 70 holes are arranged, as shown in Figure 2, in 7 columns of 10 holes each. The top plate has 16 similar holes in one quadrant arranged in 4 columns of 4 rows each. In Figure 2 holes are indicated in all four quadrants for purposes of later reference.

The faces and top are held together by screws, there being no bottom plate, and the structure so formed is attached to the circular plate shown in Figure 1. This circular plate can be rotated with respect to a second square plate below, this second plate being fastened to the tunnel floor or to a platform to be described later. Both plates have a 3 -inch opening in the center to permit the passage of the rubber connecting tubes. The circumferential edge of the circular plate is marked at intervals of $5^{\circ}$, and the square stationary plate has an index mark at the center of its upstream face. 
Scientific Papers of the Bureau of Standards, Vol. 20

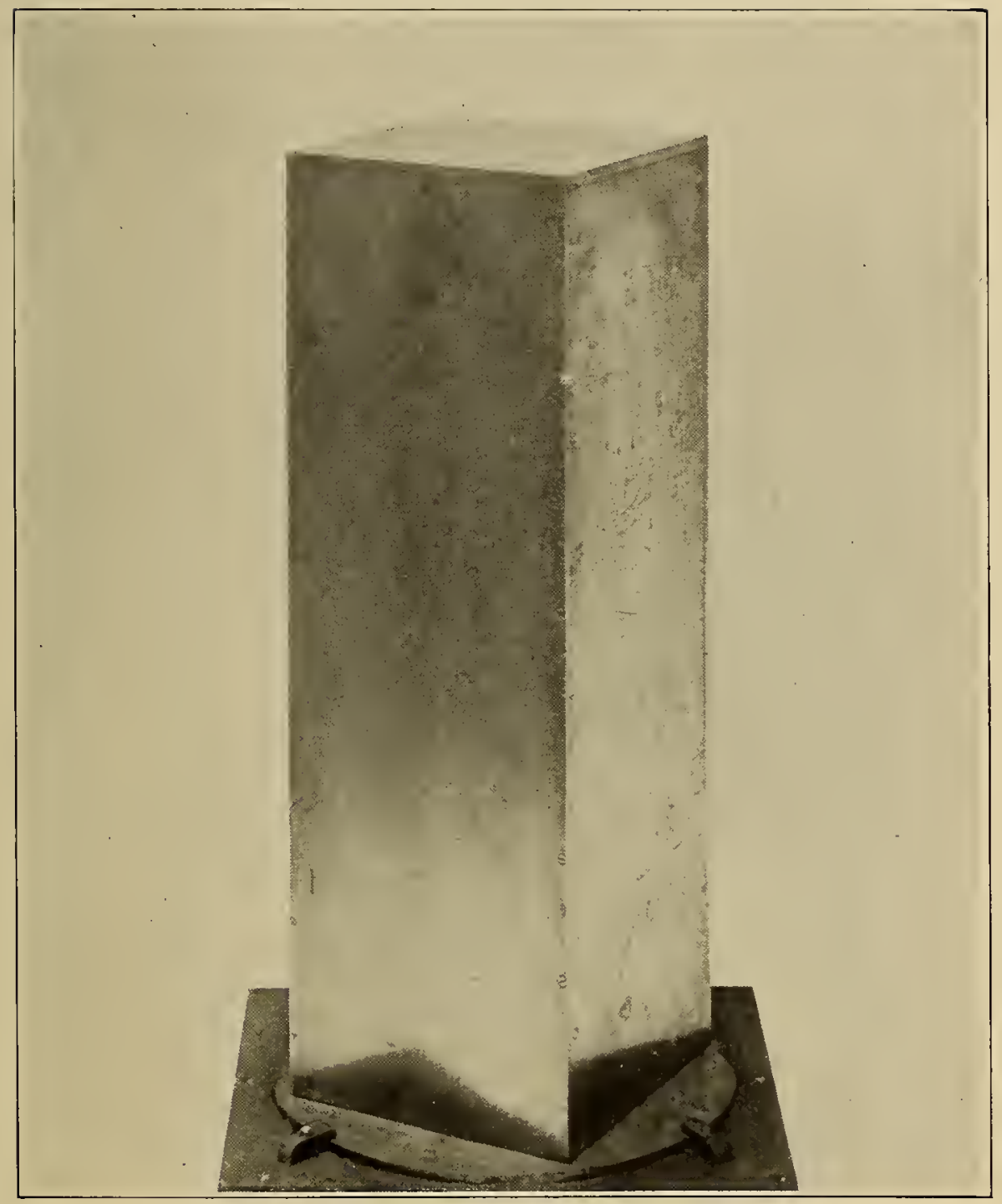

FIG. 1.-The model 


\section{THE WIND STREAM}

The wind stream used was that in the largest of the three wind tunnels at the Bureau of Standards. The tunnel differs from all existing types (see fig. 3 ), in that it is not housed in a building, but stands in the open. In all other respects it is of the National Physical Laboratory type. It is of circular cross section, 92 feet in length, and consists of three sections. The working portion is a cylinder 10 feet in diameter and 50 feet long; models being placed about 27 feet from the entrance end of the cylinder. The entrance is a short faired section, 4 feet long and 14 feet in diameter at its outer end. The exit cone is 34 feet long and 14 feet 2 inches in diameter at the exit end. The axis of the tunnel is about 8 feet above the ground. To secure steady flow a honeycomb is used at the entrance to the cylindrical portion, the cells being 4 inches square and 12 inches long. A house containing the control equipment and other apparatus is located at the side of and above the tunnel at the working section.

The air is drawn through the tunnel by a 4-bladed propeller 14 feet in diameter, the propeller being driven by a 200horsepower direct-current motor. The maximum wind speed obtained is about 70 miles per hour, the propeller then turning at 550 revolutions per minute.

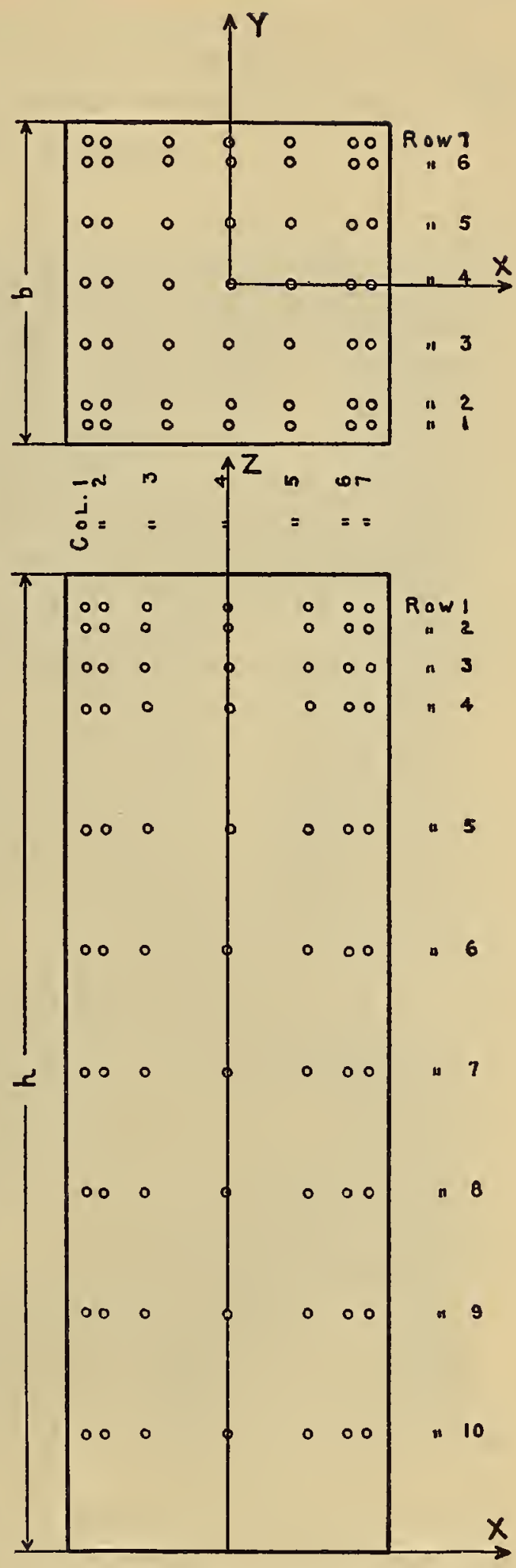

FIG. 2.-Location of holes on model and reference axes 


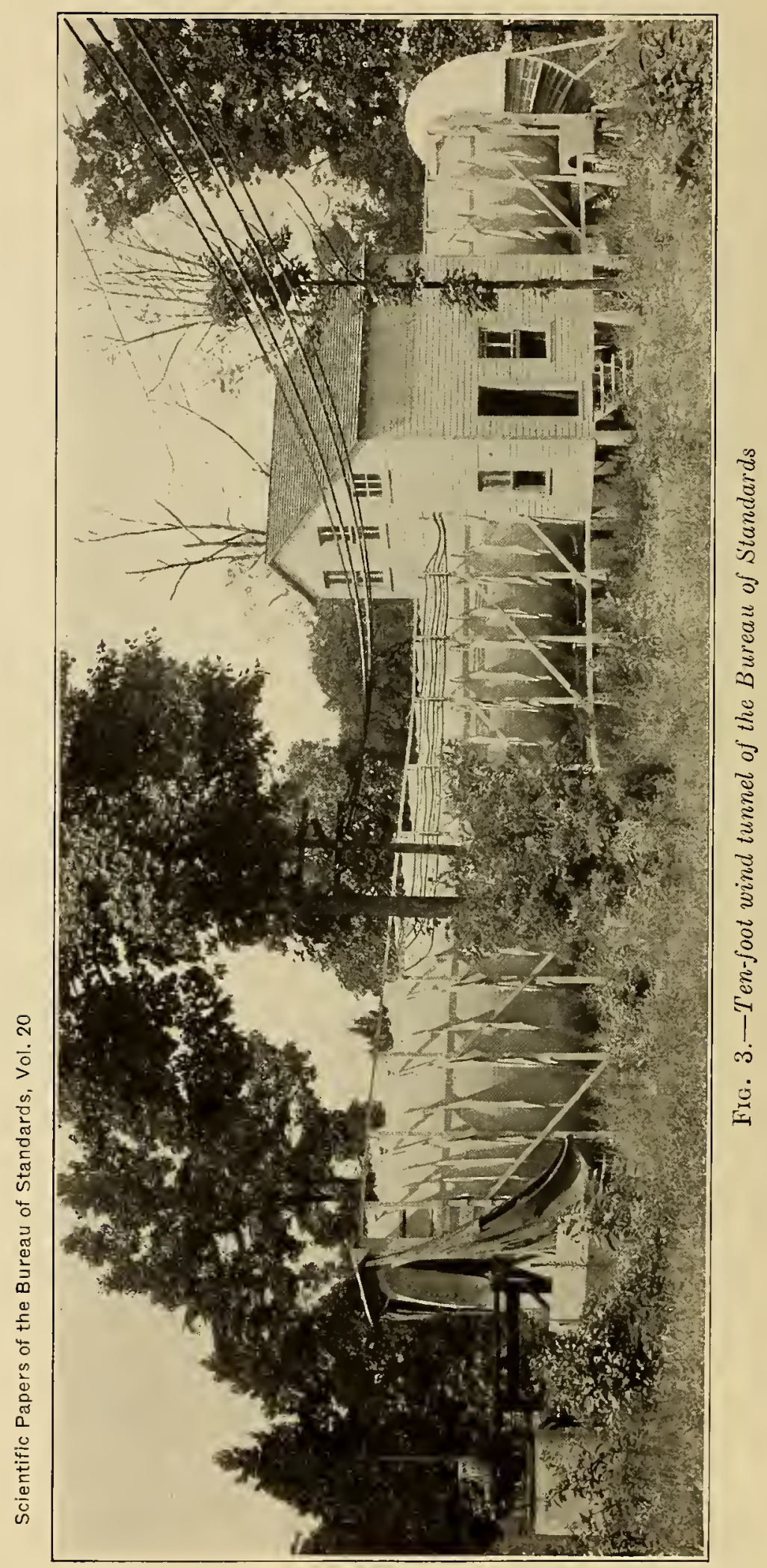


Because of its location in the open, the tunnel can be satisfactorily operated only in favorable weather; that is, when there is no precipitation or wind exceeding 3 or 4 miles per hour.

\section{SPEED MEASUREMENT}

The wind speed was measured by means of a standard Pitotstatic tube and inclined gauge. The nose of the Pitot-static tube was $21 / 2$ feet from the tunnel wall and 5 feet upstream from the model under test, being fastened to a hollow stream-lined strut which passed through the tunnel wall to the observation room. Connecting tubes were carried through the hollow strut to the inclined gauge. The inclined gauge, which was of approximately 1 to 5 slope, contained kerosene, this liquid being used because of its low freezing point. The gauge was standardized against a $U$ tube of large diameter containing benzene, the $U$ tube being read with a cathetometer.

To obtain the wind speed at the model house, the model was removed and a second Pitot-static tube set up at various stations in turn in the space previously occupied by the model.

\section{THE PRESSURE GAUGE}

To measure the pressure at various points on the surface of the house an inclined multiple-tube manometer was used. This manometer, shown in Figure 4, consisted of a large reservoir and 12 glass tubes fastened to an aluminum frame which was supported on a suitable base. On each side of the reservoir were 6 of the glass tubes, connected to it through suitable connections. The frame was clamped at a fixed angle, the slope being kept constant during the test. Kerosene was used as the gauge liquid. The tubes were standardized by comparison with a fixed inclined gauge of 1 to 10 slope which in turn had been standardized by comparison with a $U$ tube of large diameter containing benzene. This fixed gauge of 1 to 10 slope was also used during the test in the few cases where the pressures to be measured exceeded the capacity of the multiple-tube manometer.

\section{GENERAL PROCEDURE}

In an actual structure the wind pressure is modified by the presence of the ground, so that some method must be used in the artificial wind to produce the effect of the ground. In our experiments two methods were actually used. In the first the model rested directly on the tunnel floor with a small segment of wood under the front and rear edges of the lower plate to fill in the space left due to the curvature of the tunnel wall. In this case the wind is not uniform over the region occupied by the model and the reduction in speed near the floor is probably greater than that existing near the ground in an 
Scientific Papers of the Bureau of Standards, Vol. 20

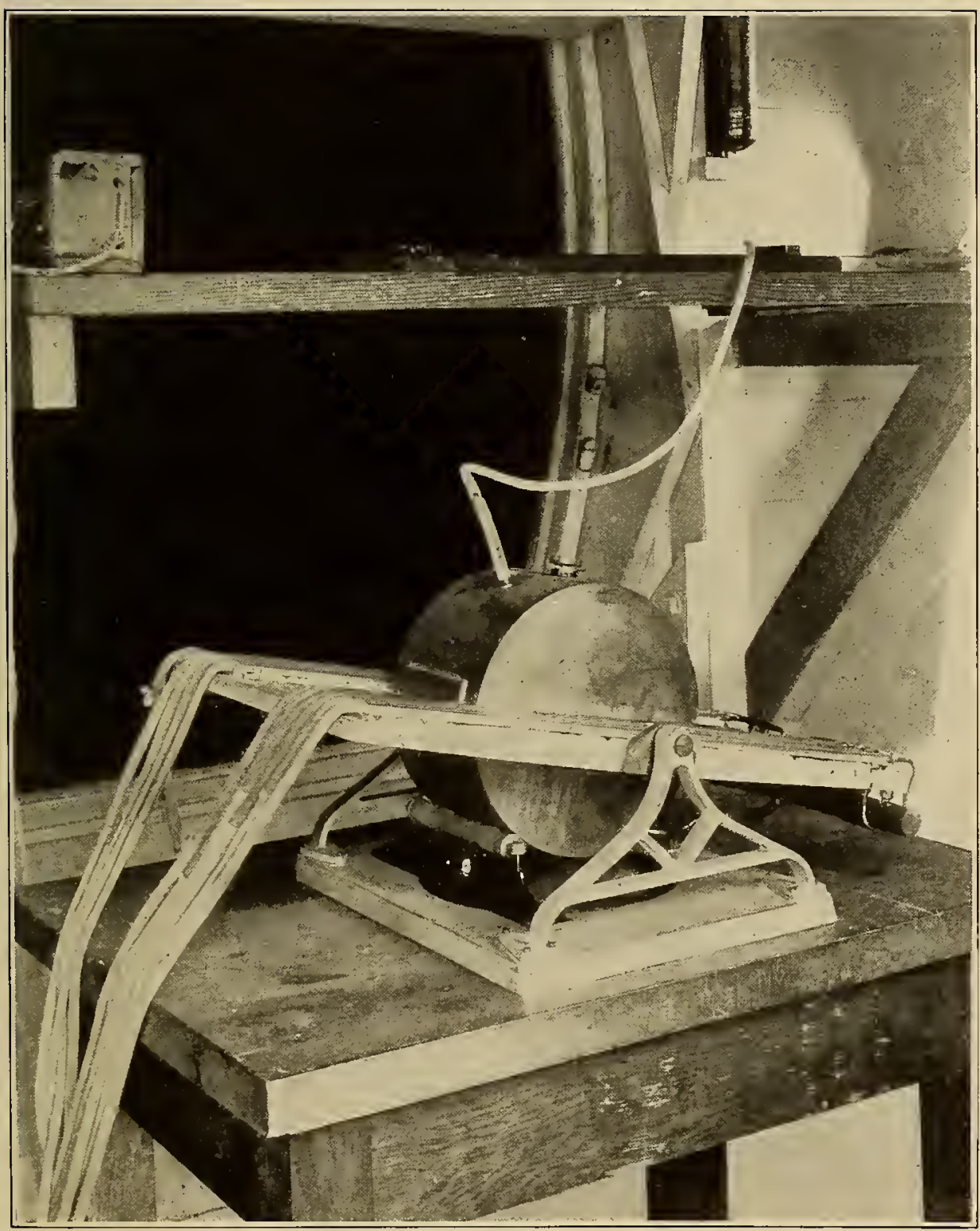

Fig. 4.-Multiple slope gauge used for pressure measurements 
actual wind. The distribution is approximately that shown in Figure 5, which represents the variation in wind speed along the axis of the house. The speeds at other points in the area are somewhat different, but the variation is within the limits indicated.

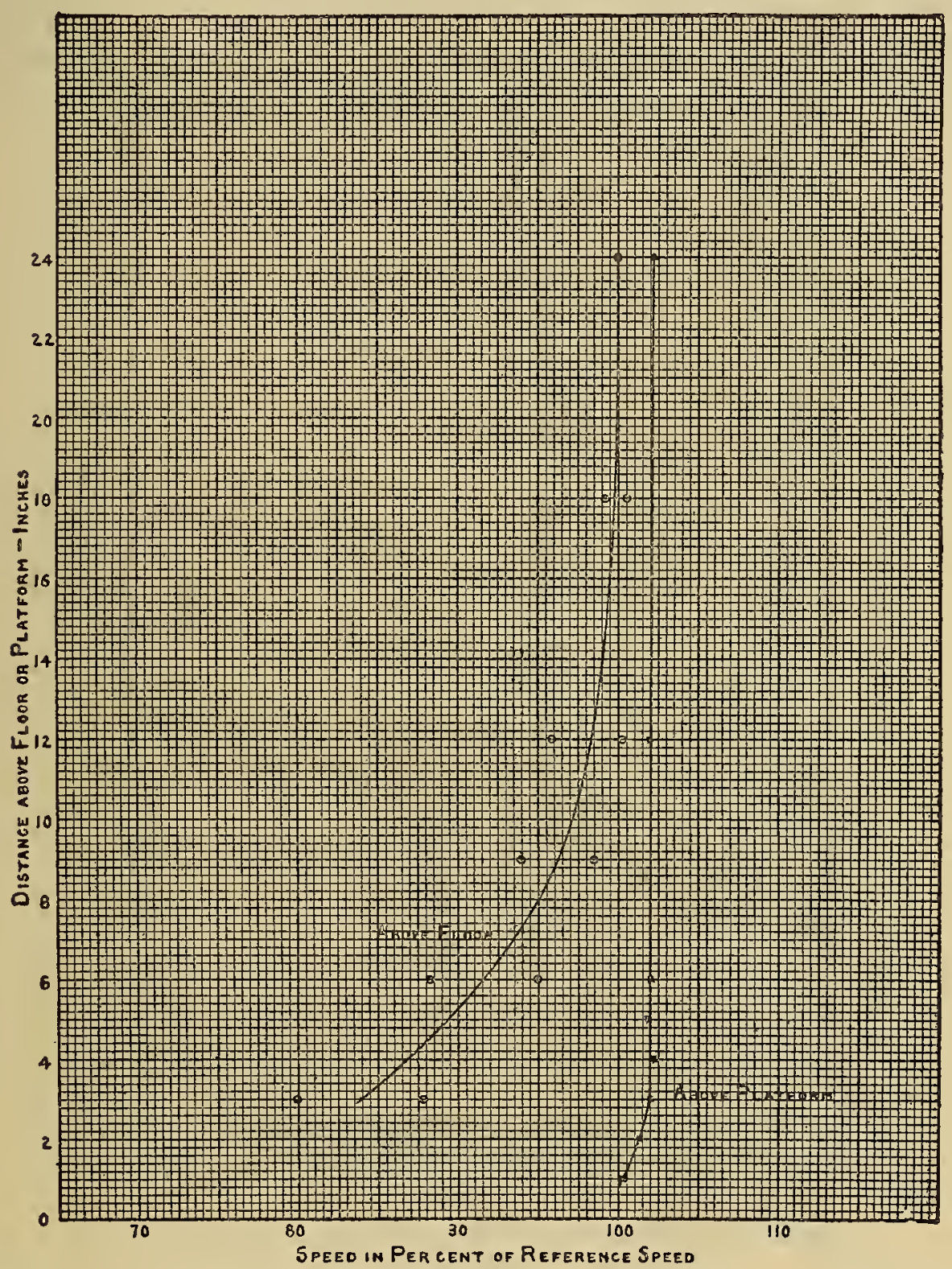

Fig. 5.-Variation of wind speed above the tunnel floor and above the platform in the absence of the model

The circles represent the maximum and minimum velocities at the height indicated

In the second method of representing ground effect the model was placed on the center of a platform which extended completely across the tunnel and which was 2 feet above the tunnel floor at the center. The platform extended 5 feet in the direction of the wind and had its 
upstream edge beveled to reduce the disturbance produced. The speed is in this case nearly constant to within a few inches of the platform as shown in Figure 5, and is higher than the reference speed because of the constriction of the tunnel area.

The procedure for making the observations was the same for both set-ups. The model house was first set with the face containing the pressure holes normal to the wind direction, a condition designated

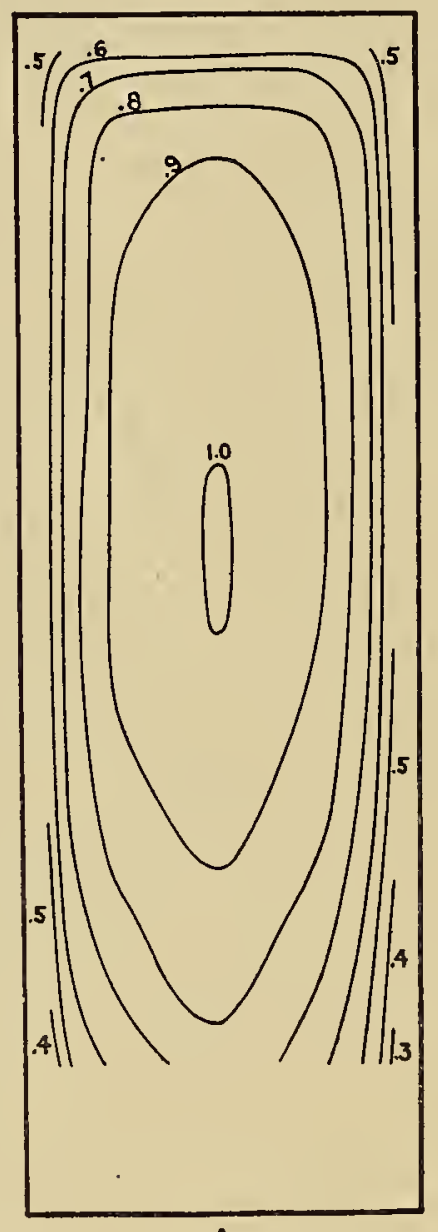

A

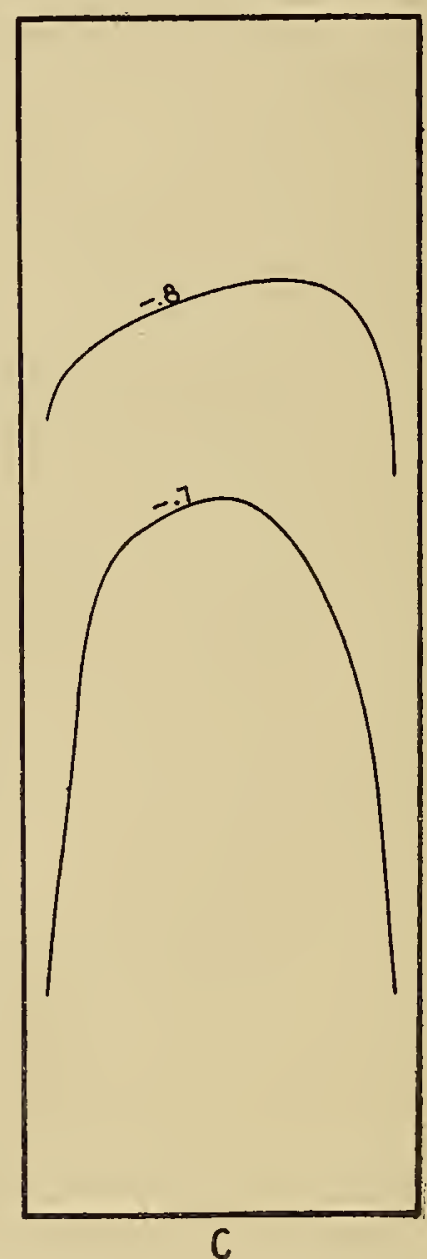

FIG. 6.-Pressure distribution over $A$ and $C$ faces shown by equal pressure contours. Face $A$ at $90^{\circ}$. Model on tunnel floor.

See Figure 7 for B and D faces, Figure 8 for top. Pressures are given as fractions of the velocity pressure $1 / 2 \rho V^{2}$

as $90^{\circ}$ in both the diagrams and tables. The 10 holes of one column were then connected to 10 of the tubes of the multiple-tube manometer, the reservoir of the manometer being connected to a small hole in a static plate located $73 / 4$ feet upstream from the model. Two observers were engaged in the measurements. One observer adjusted the wind speed to the proper value and signaled the second observer when the speed was steady and of the correct magnitude. 
The second observer read the 10 tubes of the multiple gauge, which gave the differences in pressure between the holes at the surface of the model and that at the static plate upstream. The procedure was repeated for three additional wind speeds, the speeds used being approximately $40,60,80$, and 100 feet per second $(27.3,40.9$, 54.5 , and 68.2 miles per hour). The house was then turned through $15^{\circ}$ and a similar group of measurements made, the process being

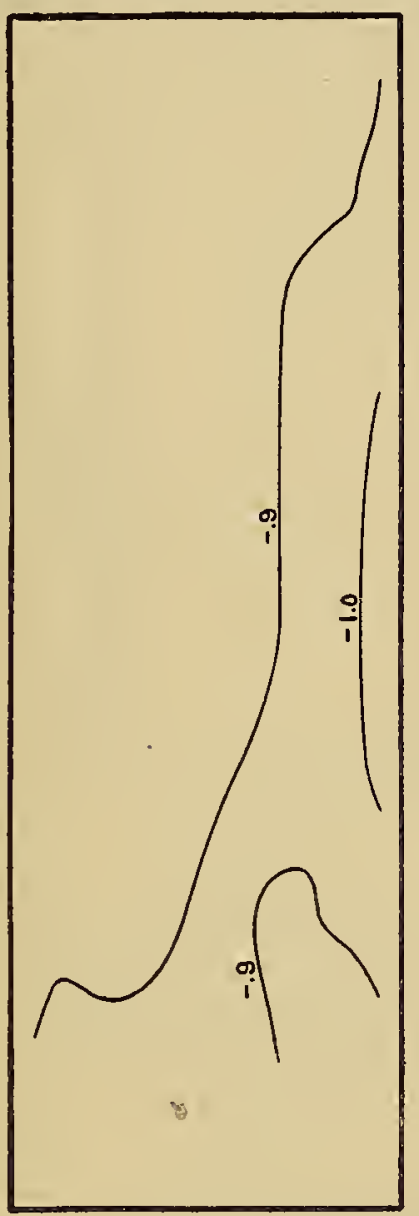

B

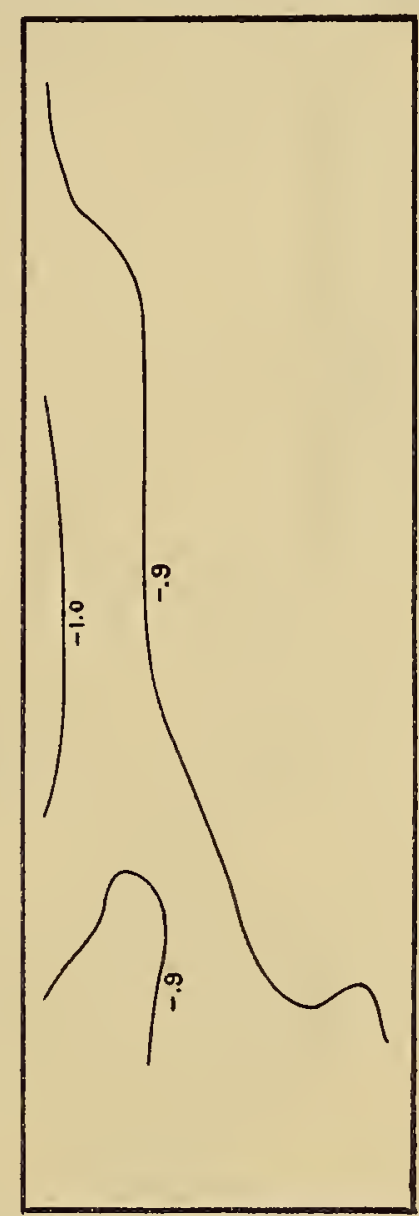

D

FIG. 7.-Pressure distribution over $B$ and $D$ faces shown by equal pressure contours. Face $A$ at $90^{\circ}$. Model on tunnel floor

See Figure 6 for $\mathrm{A}$ and $\mathrm{C}$ faces, Figure 8 for top. Pressures are given as fractions of the velocity pressure $1 / 2 \rho V^{2}$

continued until the face of the house had turned through an angle of $180^{\circ}$, the final angle being designated as $270^{\circ}$.

The 10 connections were then placed on a new column of holes and a similar series of measurements made, this procedure being continued until the entire 70 holes had been tested at 90,105, 120, $135,150,165,180,195,210,225,240,255$, and $270^{\circ}$ at the four wind speeds. The complete series of measurements furnish the data for the pressure distribution over any face at any wind direction. 
An entirely similar procedure was followed for the top, except that eight holes were connected at one time and the house turned through $360^{\circ}$ in order that the quadrant containing the holes might occupy all possible positions.

\section{REDUCTION OF OBSERVATIONS}

The results finally desired are the changes in pressure produced by the presence of the house. These changes might be expressed in

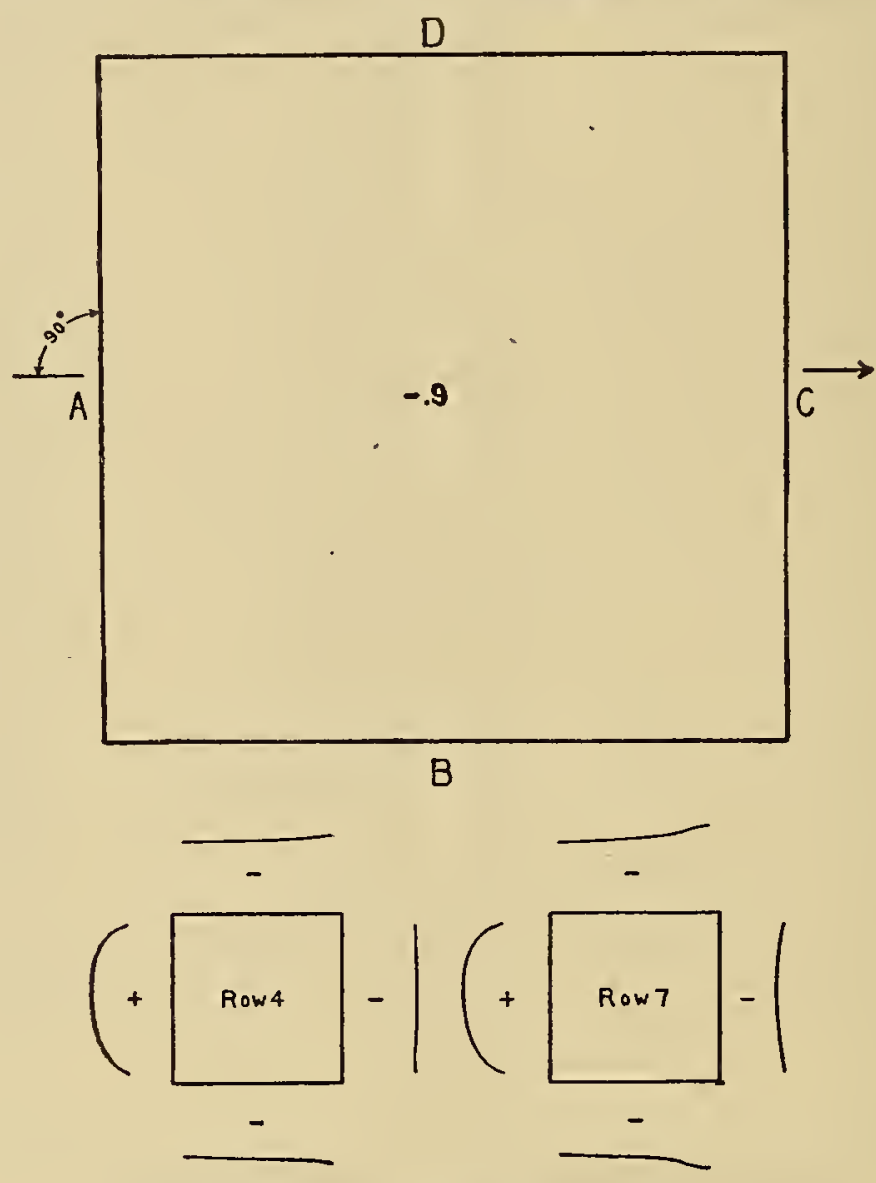

Fig. 8.-Pressure distribution over top shown by equal pressure contours. Face $A$ at $90^{\circ}$. Model on tunnel floor

See Figure 6 for $A$ and $C$ faces, Figure 7 for B and D faces. Pressures are given as fractions of the velocity pressure $1 / 2 \rho V^{2}$

Below. Sections through face contours at rows 4 and 7. (See Figure 2 for location)

pounds per square foot or in any other convenient units, but, as explained in Part I of this paper, it is advantageous to express them as fractions of the velocity pressure. (See Table 1.) Two corrections are necessary-one to allow for the difference in speed between the reference Pitot-static tube and the model, the second to allow for the difference between the reference pressure used in making the measurements and the static pressure at the area occupied by the 
model. When the house is mounted on the tunnel floor, both corrections are negligible (the reduction in speed over the lower part of the house being ignored), but when the house is mounted on the platform, both are of an appreciable magnitude.

The procedure in reducing the observations was as follows: The gauge readings observed on the multiple-tube manometer were reduced to absolute pressure differences in pounds per square foot and
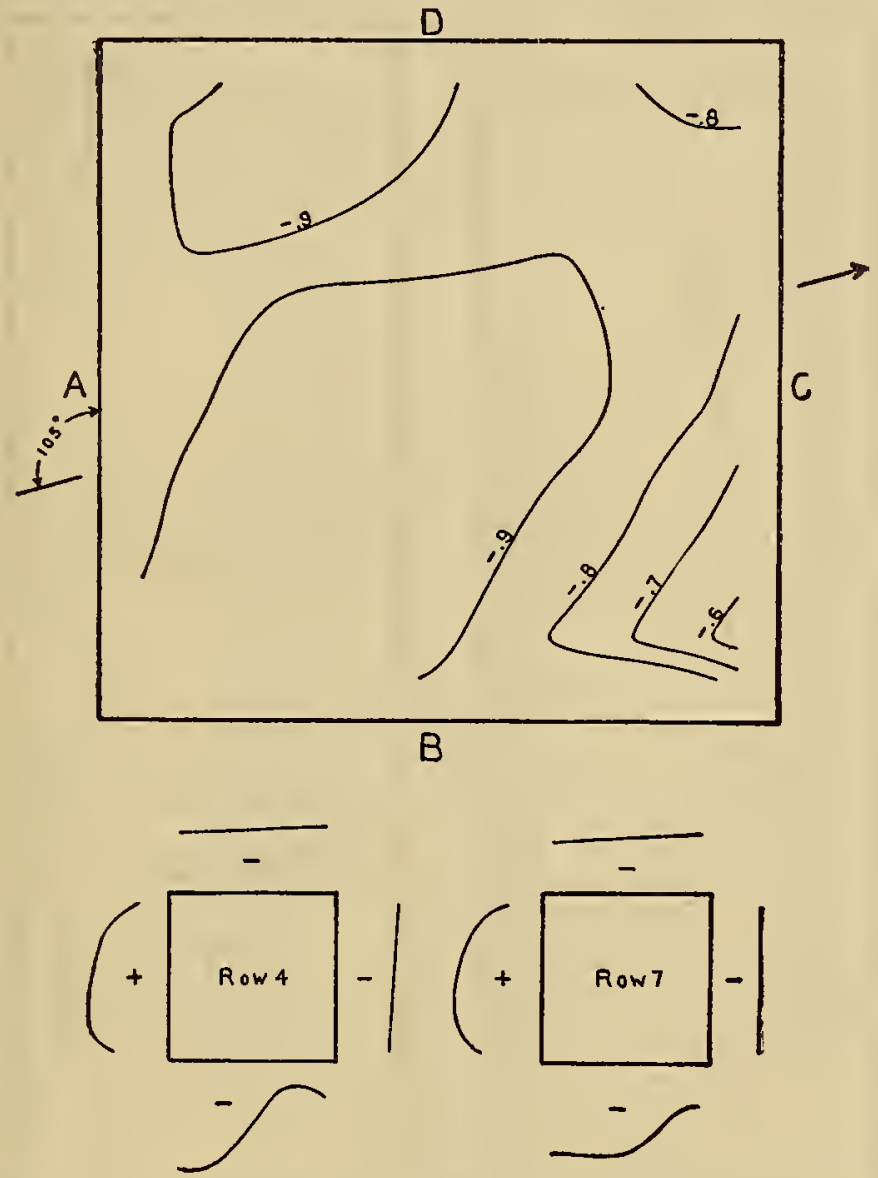

Fig. 9.-Pressure distribution over top shown by equal pressure contours. Face $A$ at $105^{\circ}$. Model on tunnel floor

See Figure 10 for $\mathrm{A}$ and $\mathrm{C}$ faces, Figure 11 for $\mathrm{B}$ and $\mathrm{D}$ faces. Pressures are given as fractions of the velocity pressure $1 / 2 \rho V^{2}$

Below. Sections through face contours at rows 4 and 7 . See Figure 2 for location

were then expressed as fractions of the velocity pressure indicated by the reference Pitot-static tube. The two corrections mentioned above were then applied. The values at each station for the four wind speeds were then averaged and the results collected so as to give the distribution over the entire house for a given wind direction. The designation of faces is indicated in Figures 8, 9, 14, and 15, which show views looking down on top of the house. The faces $70336^{\circ}-26^{*}-3$ 
are called A, B, C, D in a counterclockwise direction when viewed from above. All angles are measured from face $A$, and the house is rotated in a clockwise direction when viewed from above. The information available gives the distribution over the front and rear faces $\mathrm{A}$ and $\mathrm{C}$, and over one side face, $\mathrm{D}$, when face $\mathrm{A}$ is at $90^{\circ}$. Face $B$ is assumed the same as face D. At 105 and $120^{\circ}$ angle of face $\mathrm{A}$, the data give the distribution over all faces. At $135^{\circ}$ angle

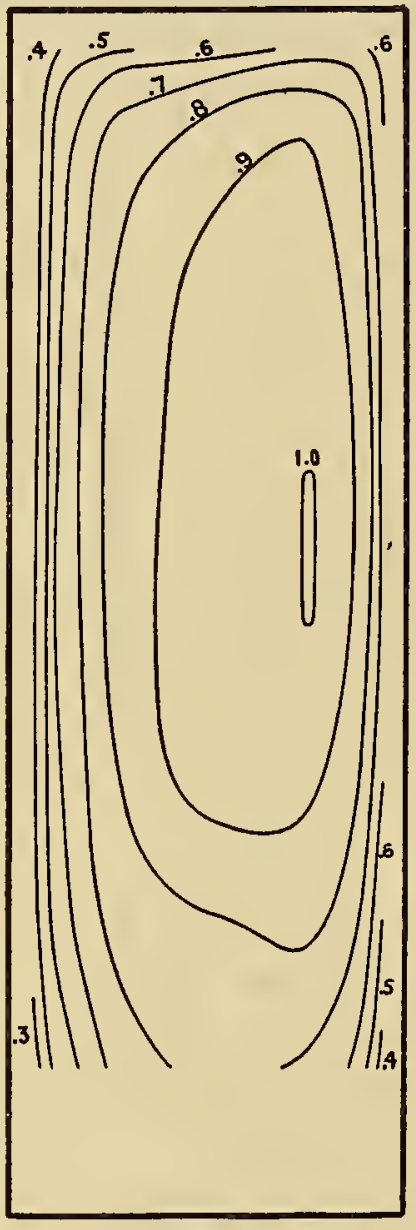

A

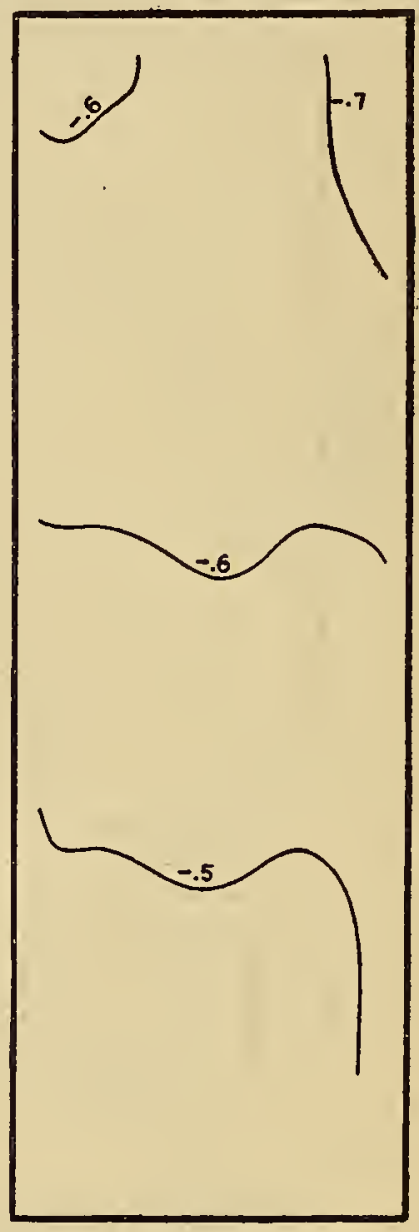

C

FIG. 10.-Pressure distribution over $A$ and $C$ faces shown by equal pressure contours. Face $A$ at $105^{\circ}$. Model on tunnel floor

See Figure 11 for $B$ and D faces, Figure 9 for top. Pressures are given as fractions of the velocity pressure $1 / 2 \rho V^{2}$

of face $A$, the data give the distribution over faces $A$ and $D, B$ being assumed the same as $A$, and $C$ the same as $D$. In many cases the distribution over a face has been obtained from a measurement over face $A$ when $A$ was at an angle to the wind of the same magnitude but of opposite sign. For example, the distribution over face B, when face $A$ is at $105^{\circ}$, is inferred from the distribution on face $A$ when face $A$ is at $165^{\circ}$. 


\section{RESULTS}

The results of the measurements with the ground effect produced by the platform are given in Tables $2,3,4$, and 5 in the form of tabulated values of the pressures at the various stations expressed as fractions of the velocity pressure. The location and designation of stations on the faces is shown in the lower part of Figure 2, which represents any face when viewed from the exterior of the house. In

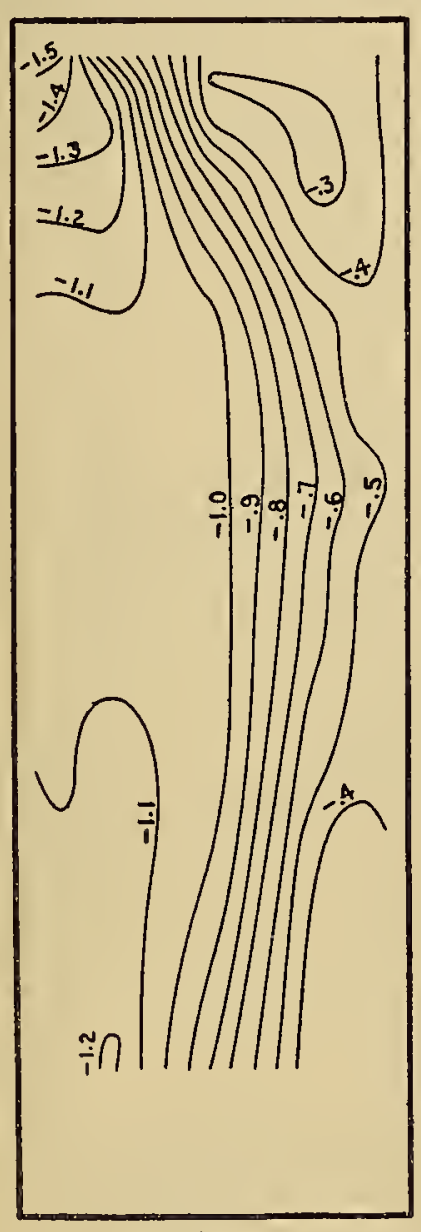

B

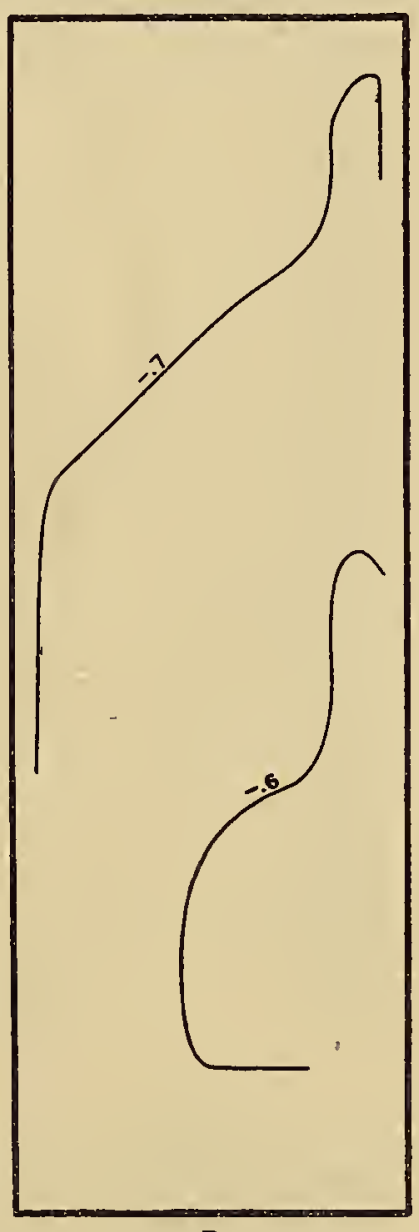

D

Fig. 11.-Pressure distribution over $B$ and $D$ faces shown by equal pressure contours. Face $A$ at $105^{\circ}$. Model on tunnel floor

See Figure 10 for $\mathrm{A}$ and $\mathrm{C}$ faces, Figure 9 for top. Pressures are given as fractions of the velocity pressure $1 / 2 \rho V^{2}$

the case of the top, row 1 is adjacent to the face from which the wind direction is measured; that is, face $A$.

The results for the measurements with ground effect produced by the tunnel floor are represented in the form of contour maps (figs. 6 to 17), the contour interval being one-tenth of the velocity pressure. Points along the same contour show the same pressure on the house. 
Horizontal sections of the contours taken at rows 4 and 7 are shown just below the contours for the top of the house (figs. 8, 9, 14, and 15), these sections being pictures giving the relative magnitudes of the increases and decreases in pressure on the four faces. Both increases and decreases are plotted outward, but are distinguished by plus and minus signs. In both tables and contours increases in pressure above

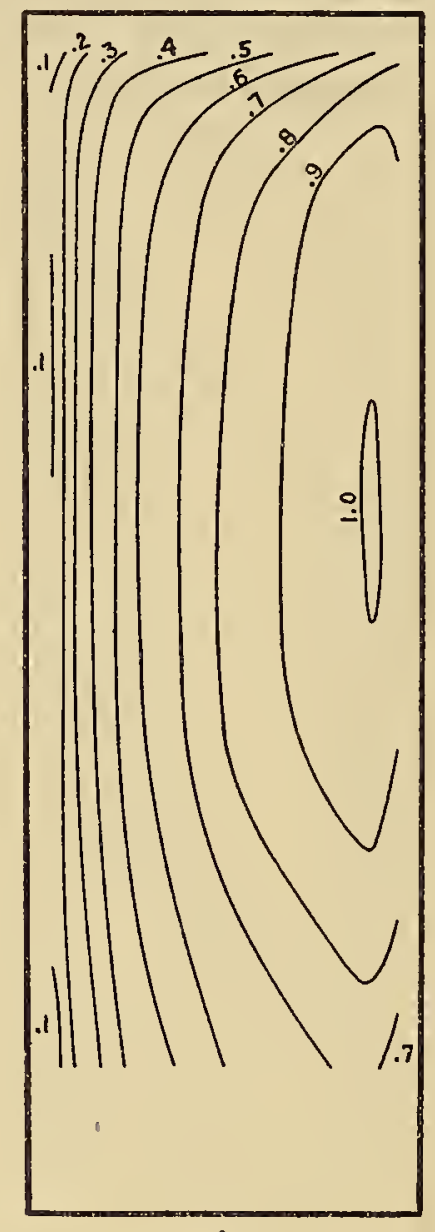

A

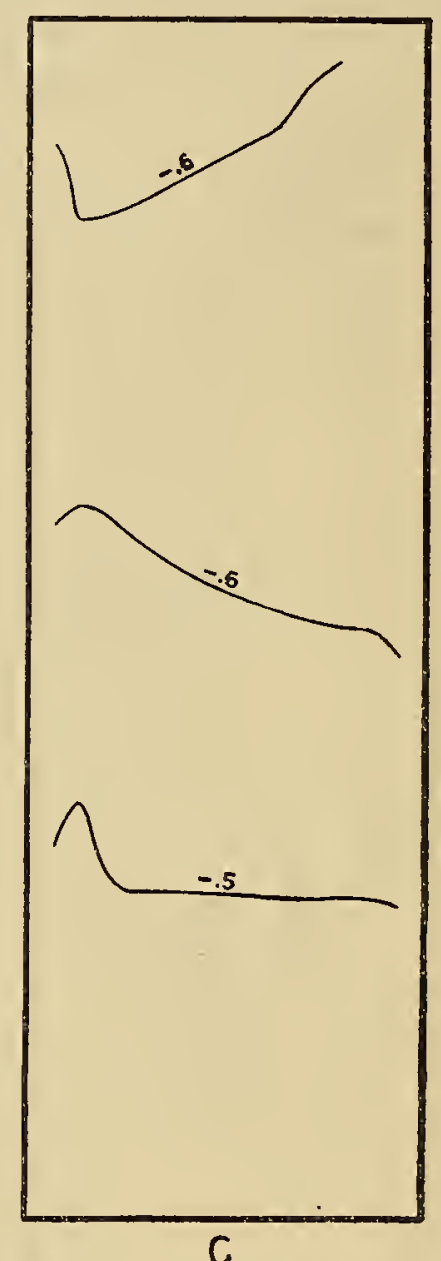

C

FIG. 12.-Pressure distribution over $A$ and $C$ faces shown by equal pressure contours. Face A at $120^{\circ}$. Model on tunnel floor

See Figure 13 for B and D faces, Figure 14 for top. Pressures are given as fractions of the velocity pressure $1 / 2 \rho V^{3}$

the static pressure are designated by plus signs and decreases by minus signs.

The resultant force acting on each face and its point of application were computed by a process of numerical integration. The resultant force varies with the wind speed and for a larger or smaller model would depend on the size, so that in expressing the results it is convenient to use coefficients which are nearly independent of speed and size and which may be used to compute the force at different 
wind speeds on structures resembling the model. Thus, since the force varies approximately as the area, the computed force on each face has been divided by the area of the face and the computed force on the top has been divided by the area of the top. Furthermore, since the force varies approximately as the velocity pressure, the forces have further been divided by the velocity pressure. Forces are called positive when due to increases in pressure. Figure 18

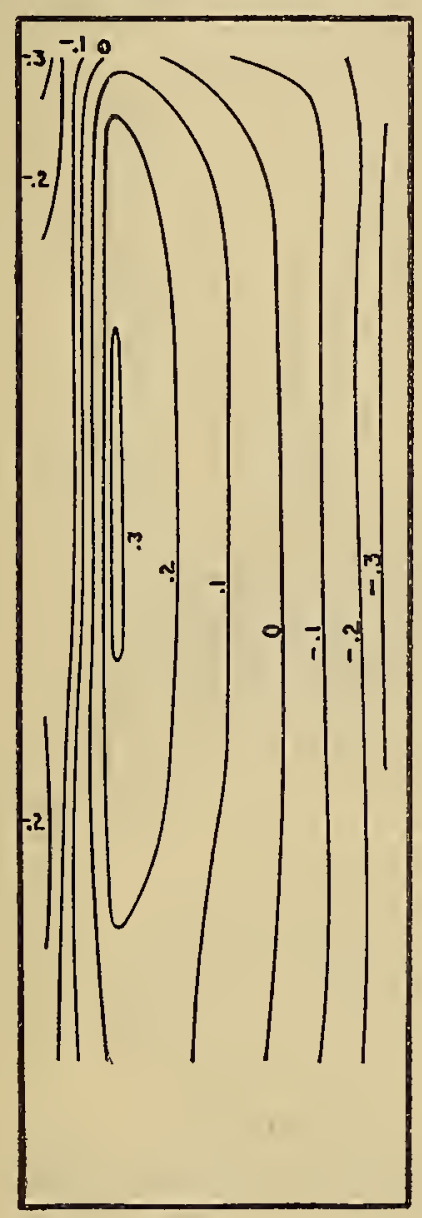

$\mathrm{B}$

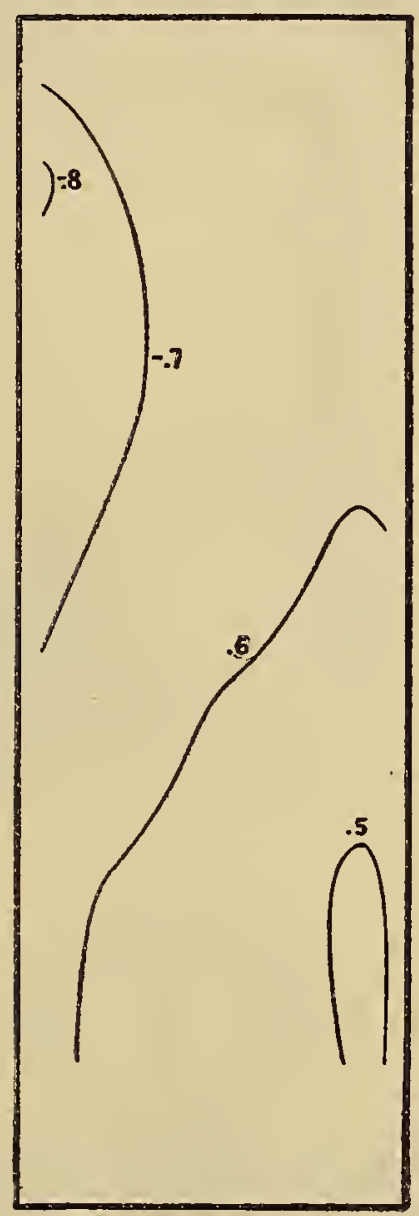

D

FIG. 13.-Pressure distribution over $B$ and $D$ faces shown by equal pressure contours. Face $A$ at $120^{\circ}$. Model on tunnel floor

See Figure 12 for $\mathrm{A}$ and $\mathrm{C}$ faces, Figure 14 for top. Pressures are given as fractions of the velocity pressure $1 / 2 \rho V^{2}$

shows the variation of the force coefficient with the angle of the face to the wind. As stated above, the force coefficient is defined as the ratio of the total force to the product of the area of the face (or top) and the velocity pressure. In other words, it is the ratio of the average pressure on the face to the velocity pressure.

The location of the point of application is given by its distances from the reference axes shown in Figure 2, namely, for a face, the 
base and a vertical axis through the center of the face, and for the top two axes through the centers of opposite edges. It is obvious that the distances will vary approximately as a linear dimension of the face or top so that vertical distances have been expressed as a fraction of the height and horizontal distances as a fraction of the width. These ratios are usually termed center of pressure coefficients. Figures 20 and 22 show the variation of the horizontal center of pressure coefficient with the angle of the face to the wind. ${ }^{4}$
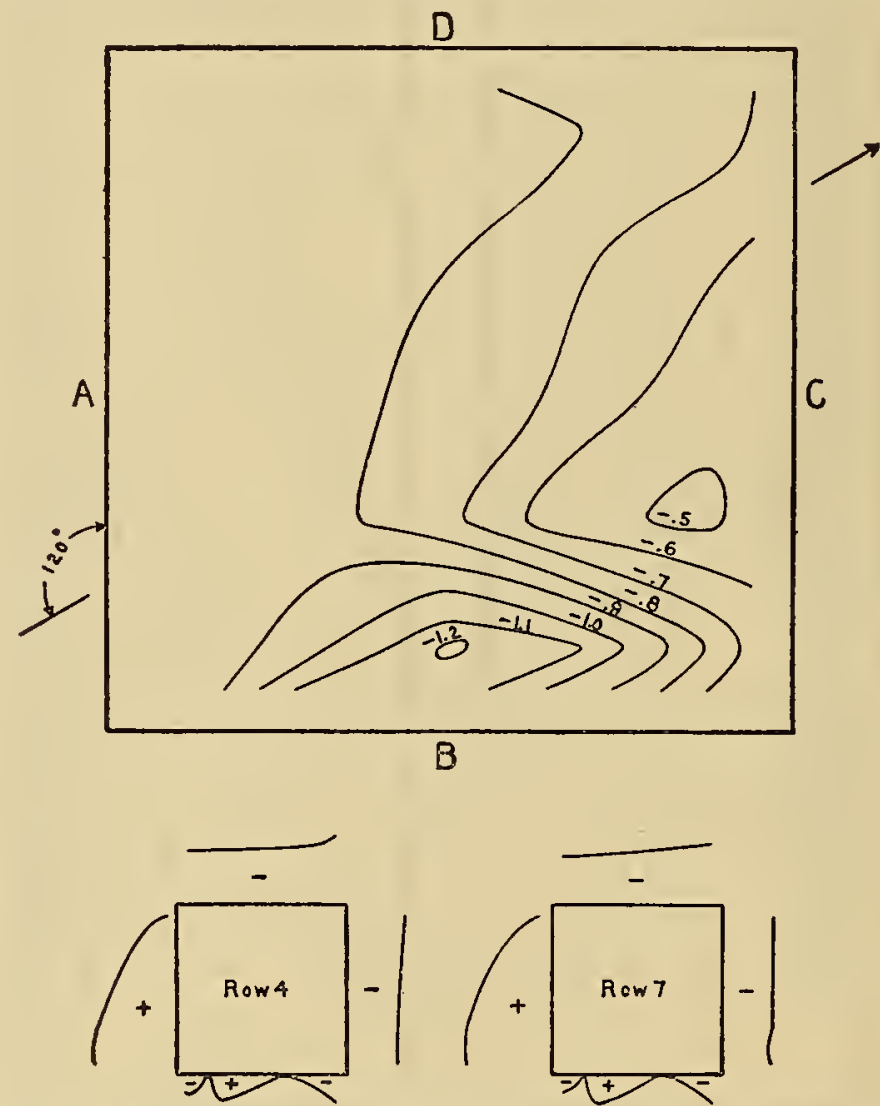

FIG. 14.-Pressure distribution over top shown by equal pressure contours. Face $A$ at $120^{\circ}$. Model on tunnel floor

See Figure 12 for $A$ and $C$ faces, Figure 13 for $B$ and $D$ faces. Pres. sures are given as fractions of the velocity pressure $1 / 2 \rho V^{2}$

Below. Sections through face contours at rows 4 and 7 . (See Figure 2 for location)

The product of force coefficient and center of pressure coefficient gives a moment coefficient about the axis from which the distance to the center of pressure is measured. Thus, the moment coefficient referring to moments about the horizontal axis (termed vertical moment coefficient) is equal to the moment about the horizontal axis divided by the product of area of face, height of face, and velocity

1 Vertical moment coefficients and center of moment are not plotted, since the center of moment is nearly constant and the moment curve is similar to the force curve, moment coefficient being approximately onehalf the force coefficient. (See Table 6.) 
pressure; and the moment coefficient referring to moments about the vertical axis (termed horizontal moment coefficient) is equal to the moment about the vertical axis divided by the product of area of face, width, and velocity pressure. Figures 19 and 21 show horizontal moment coefficients for the face and top. The signs of moments follow the usual right-hand screw convention; that is, a positive

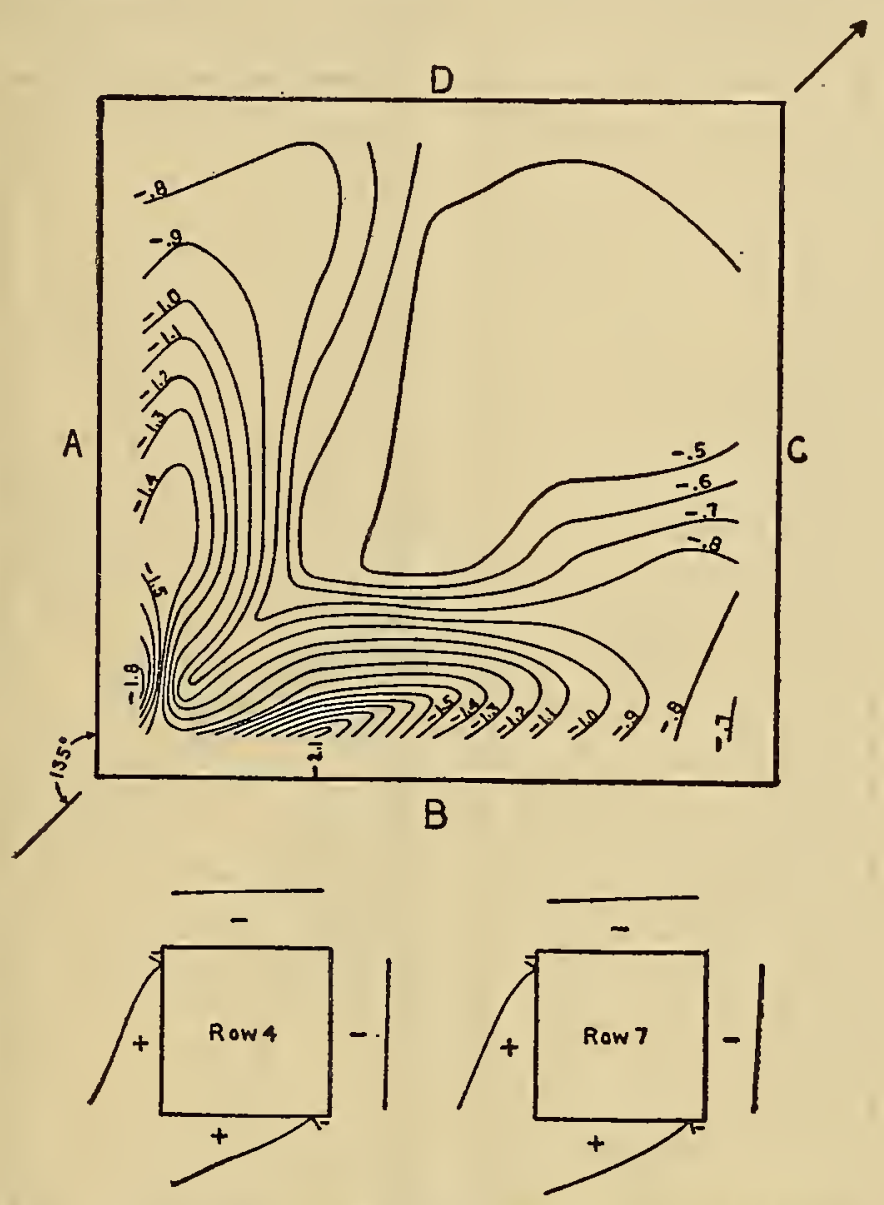

Fig. 15.-Pressure distribution over top, shown by equac pressure contours. Face $A$ at $135^{\circ}$. Model on tunnel floor

See Figure 16 for $\mathrm{A}$ and $\mathrm{C}$ faces, Figure 17 for $\mathrm{B}$ and $\mathrm{D}$ faces. Pressures are given as fractions of the velocity $1 / 2 \rho V^{2}$

Below. Sections through face contours at rows 4 and 7 . (See Figure 2 for location.)

moment about any axis would cause a right-hand screw to advance along that axis in the positive direction.

The use of coefficients such as those described has another advantage in addition to the fact that they facilitate the estimation of forces and moments on models of a different size at any wind speed. The values of the coefficients do not depend on the units of measurement so long as a self-consistent system is used throughout. 
From the curves of Figures 18 to 22 resultant forces and moments on the house at any angle to wind may be computed. It is necessary, however, to adopt a new system of reference since a pressure increase on one face produces a force in the same direction as a pressure decrease on the opposite face. The system adopted is shown in Figure 23. It consists of a right-hand set of Cartesian axes fixed to the house and rotating with it. The contributions of each face and

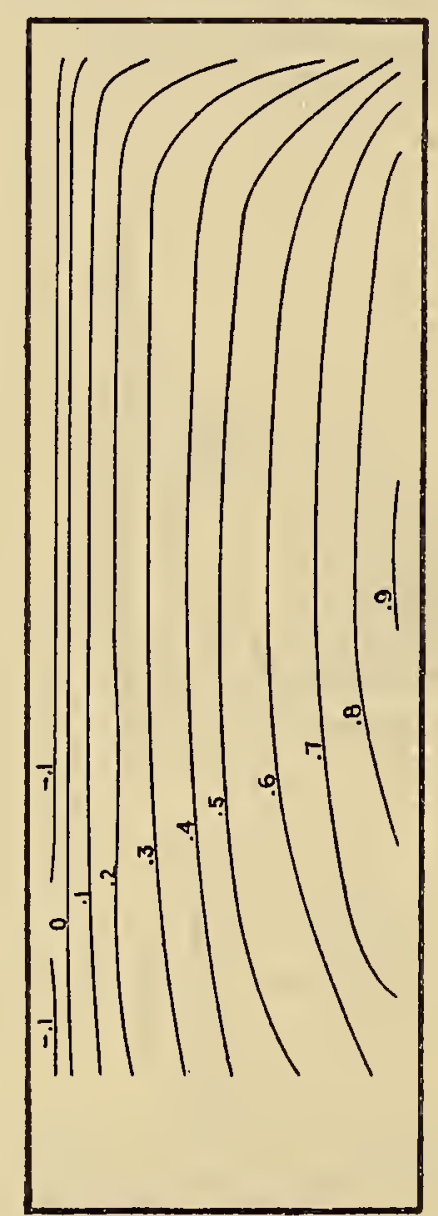

A

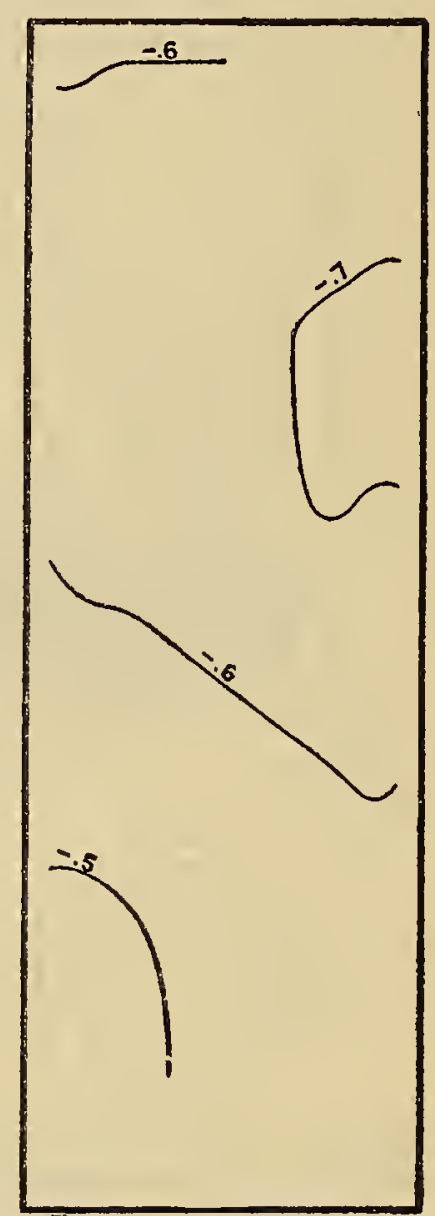

C

FIg. 16.-Pressure distribution over $A$ and $C$ faces shown by equal pressure contours. Face $A$ at $135^{\circ}$. Model on tunnel floor

See Figure 17 for $B$ and D faces, Figure 15 for top. Pressures are given as fractions of the velocity pressure $1 / 2 \rho V^{2}$

the resultants are shown in Table 6 , coefficients being defined in the same manner as before.

\section{ACCURACY}

The accuracy of any individual measurement depends to a large extent on the particular station referred to and on the angle of the model to the wind. In general, an accuracy of about 3 per cent 
can be claimed, but in extreme cases the results are uncertain by 10 per cent, primarily because of large local variations in pressure at certain stations. At a relatively few stations there was evidence of a large scale effect on the pressure, the ratio of observed pressure to velocity pressure changing rapidly with speed. Table 7 gives de-

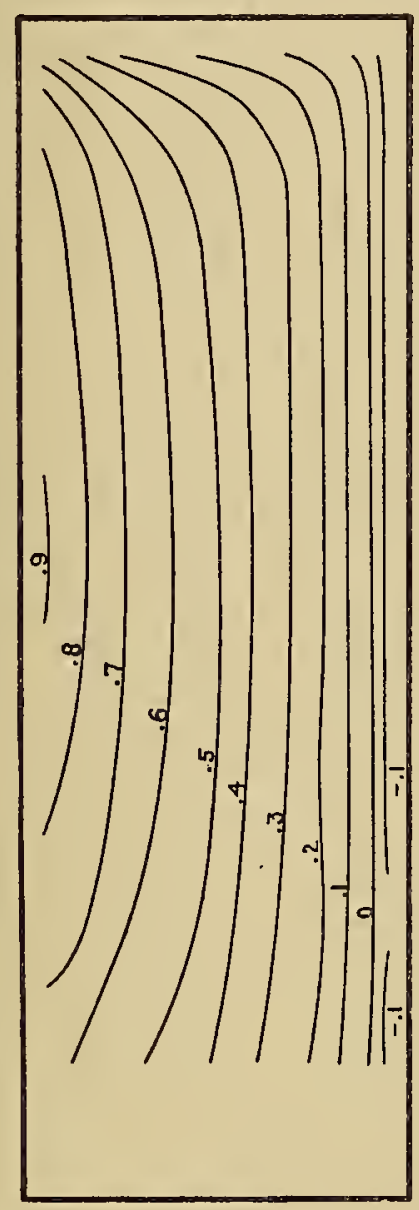

B

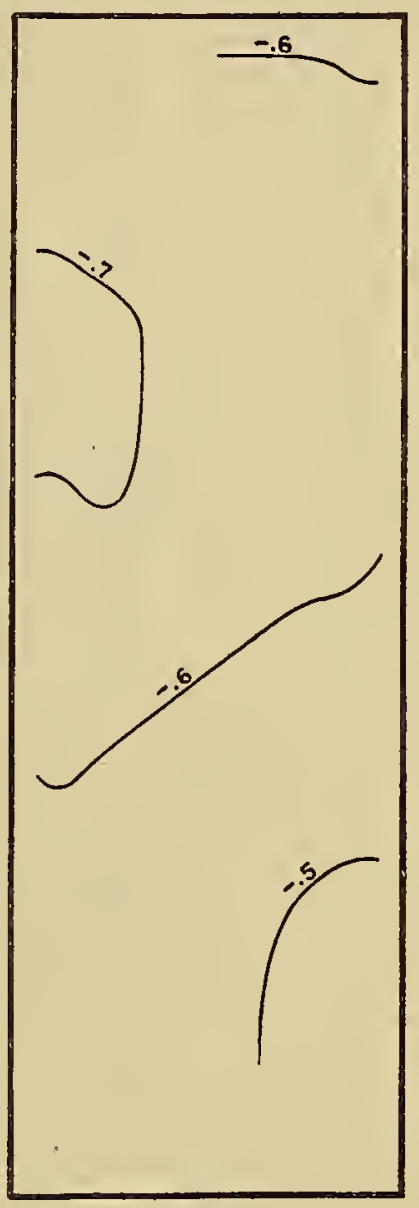

D

Fig. 17.-Pressure distribution over $B$ and $D$ faces shown by equal pressure contours. Face $A$ at $135^{\circ}$. Model on tunnel floor

See Figure 16 for $\mathrm{A}$ and $\mathrm{C}$ faces, Figure 15 for top. Pressures are given as fractions of the velocity pressure $1 / 2 \rho V^{2}$

tailed observations for a few of these stations. In general, however, the ratios were independent of wind speed.

The computed forces are believed to be correct within 3 to 5 per cent. It may be noted that the force computed from pressure measurements is theoretically not equal to the total force on the house since skin friction is neglected, but the frictional force on a body of the type studied is extremely small. 
TABLE 2.-Pressure distribution over model, platform mounting, face $A$ at $90^{\circ}$ [See fig. 8 for designation of faces]

FACE A

\begin{tabular}{|c|c|c|c|c|c|c|c|}
\hline Hole number & $\underset{1}{\text { Column }}$ & $\underset{2}{\text { Column }}$ & $\underset{3}{\text { Column }}$ & $\underset{4}{C}$ Column & $\underset{5}{\text { Column }}$ & $\underset{6}{\text { Column }}$ & $\underset{7}{\text { Column }}$ \\
\hline $\begin{array}{l}1 \\
1 \\
2 \\
3 \\
4 \\
5-\cdots-\cdots-1\end{array}$ & $\begin{array}{l}0.41 \\
.48 \\
.51 \\
.52 \\
.53\end{array}$ & $\begin{array}{l}0.53 \\
.62 \\
.71 \\
.74 \\
.73\end{array}$ & $\begin{array}{l}0.57 \\
.71 \\
.83 \\
.87 \\
.92\end{array}$ & $\begin{array}{r}0.58 \\
.72 \\
.86 \\
.93 \\
1.00\end{array}$ & $\begin{array}{r}0.55 \\
.67 \\
.79 \\
.84 \\
.88\end{array}$ & $\begin{array}{l}0.51 \\
.60 \\
.68 \\
.69 \\
.73\end{array}$ & $\begin{array}{r}0.39 \\
.46 \\
.49 \\
.52 \\
.51\end{array}$ \\
\hline $\begin{array}{l}6 \\
6 \\
6 \\
8 \\
9 \\
9\end{array}$ & $\begin{array}{l}.52 \\
.52 \\
.52 \\
.56 \\
.57\end{array}$ & $\begin{array}{l}.74 \\
.73 \\
.73 \\
.76 \\
.77\end{array}$ & $\begin{array}{l}.95 \\
.94 \\
.90 \\
.94 \\
.94\end{array}$ & $\begin{array}{l}1.00 \\
1.00 \\
1.00 \\
1.00 \\
1.00\end{array}$ & $\begin{array}{l}.90 \\
.89 \\
.88 \\
.90 \\
.90\end{array}$ & $\begin{array}{l}.73 \\
.73 \\
.72 \\
.73 \\
.74\end{array}$ & $\begin{array}{l}.52 \\
.52 \\
.51 \\
.55 \\
.55\end{array}$ \\
\hline
\end{tabular}

FACE C

\begin{tabular}{|c|c|c|c|c|c|c|c|}
\hline 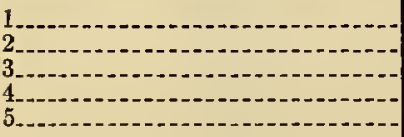 & $\begin{array}{r}-0.83 \\
-.82 \\
-.82 \\
-.83 \\
-.81\end{array}$ & $\begin{array}{r}-0.83 \\
-.83 \\
-.82 \\
-.83 \\
-.81\end{array}$ & $\begin{array}{r}-0.82 \\
-.82 \\
-.81 \\
-.81 \\
-.80\end{array}$ & $\begin{array}{r}-0.78 \\
-.79 \\
-.77 \\
-.78 \\
-.75\end{array}$ & $\begin{array}{r}-0.82 \\
-.82 \\
-.81 \\
-.82 \\
-.81\end{array}$ & $\begin{array}{r}-0.82 \\
-.83 \\
-.81 \\
-.82 \\
-.79\end{array}$ & $\begin{array}{r}-0.81 \\
-.82 \\
-.81 \\
-.82 \\
-.81\end{array}$ \\
\hline $\begin{array}{l}6 \\
6 \\
\end{array}$ & $\begin{array}{l}-.79 \\
-.75 \\
-.72 \\
-.63 \\
-.60\end{array}$ & $\begin{array}{l}-.76 \\
-.72 \\
-.66 \\
-.60 \\
-.55\end{array}$ & $\begin{array}{l}-.76 \\
-.70 \\
-.64 \\
-.56 \\
-.52\end{array}$ & $\begin{array}{l}-.73 \\
-.67 \\
-.62 \\
-.56 \\
-.50\end{array}$ & $\begin{array}{l}-.76 \\
-.73 \\
-.66 \\
-.57 \\
-.52\end{array}$ & $\begin{array}{l}-.75 \\
-.73 \\
-.69 \\
-.62 \\
-.58\end{array}$ & $\begin{array}{r}-.78 \\
-.74 \\
-.71 \\
-.63 \\
-.60\end{array}$ \\
\hline
\end{tabular}

FACE B, OR D IF REVERSED RIGHT TO LEFT

\begin{tabular}{|c|c|c|c|c|c|c|c|}
\hline 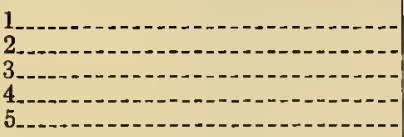 & $\begin{array}{r}-0.80 \\
-.81 \\
-.79 \\
-.79 \\
-.79\end{array}$ & $\begin{array}{r}-0.82 \\
-.82 \\
-.80 \\
-.81 \\
-.80\end{array}$ & $\begin{array}{r}-0.81 \\
-.81 \\
-.80 \\
-.81 \\
-.80\end{array}$ & $\begin{array}{r}-0.80 \\
-.81 \\
-.79 \\
-.80 \\
-.81\end{array}$ & $\begin{array}{r}-0.82 \\
-.82 \\
-.81 \\
-.81 \\
-.83\end{array}$ & $\begin{array}{r}-0.80 \\
-.80 \\
-.80 \\
-.82 \\
-.84\end{array}$ & $\begin{array}{r}-0.82 \\
-.82 \\
-.82 \\
-.84 \\
-.85\end{array}$ \\
\hline $\begin{array}{l}6 \\
6 \\
\end{array}$ & $\begin{array}{l}-.79 \\
-.76 \\
-.74 \\
-.66 \\
-.69\end{array}$ & $\begin{array}{l}-.80 \\
-.78 \\
-.76 \\
-.69 \\
-.72\end{array}$ & $\begin{array}{l}-.80 \\
-.77 \\
-.75 \\
-.70 \\
-.72\end{array}$ & $\begin{array}{l}-.81 \\
-.78 \\
-.77 \\
-.73 \\
-.72\end{array}$ & $\begin{array}{l}-.84 \\
-.84 \\
-.84 \\
-.79 \\
-.76\end{array}$ & $\begin{array}{l}-.86 \\
-.86 \\
-.88 \\
-.86 \\
-.87\end{array}$ & $\begin{array}{l}-.89 \\
-.90 \\
-.91 \\
-.89 \\
-.91\end{array}$ \\
\hline
\end{tabular}

TOP

\begin{tabular}{|c|c|c|c|c|c|c|c|}
\hline 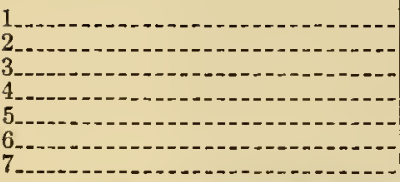 & $\begin{array}{r}-0.81 \\
-.83 \\
-.81 \\
-.81 \\
-.83 \\
-.84 \\
-.82\end{array}$ & $\begin{array}{r}-0.82 \\
-.83 \\
-.83 \\
-.84 \\
-.83 \\
-.82 \\
-.83\end{array}$ & $\begin{array}{r}-0.79 \\
-.82 \\
-.82 \\
-.82 \\
-.79 \\
-.81 \\
-.81\end{array}$ & $\begin{array}{r}-0.79 \\
-.82 \\
-.82 \\
-.83 \\
-.80 \\
-.80 \\
-.80\end{array}$ & $\begin{array}{l}-0.77 \\
-.79 \\
=.79 \\
=.78 \\
-.79 \\
-.81 \\
-.81\end{array}$ & $\begin{array}{r}-0.78 \\
-.79 \\
-.81 \\
-.80 \\
-.83 \\
-.82 \\
-.83\end{array}$ & $\begin{array}{r}-0.78 \\
-.79 \\
-.82 \\
-.81 \\
-.83 \\
-.84 \\
-.82\end{array}$ \\
\hline
\end{tabular}


TABLE 3.-Pressure distribution over model, platform mounting, face $A$ at $105^{\circ}$

[See fig. 9 for designation of faces]

TOP

\begin{tabular}{|c|c|c|c|c|c|c|c|}
\hline Hole number & $\underset{1}{\text { Column }}$ & $\underset{2}{\text { Column }}$ & $\underset{3}{\text { Column }}$ & $\underset{4}{\text { Column }}$ & $\underset{5}{\text { Column }}$ & $\underset{6}{\text { Column }}$ & $\underset{7}{\text { Column }}$ \\
\hline $\begin{array}{l}5 \\
6 \\
7 \\
7\end{array}$ & $\begin{array}{r}-0.83 \\
-.84 \\
-.92 \\
-.89 \\
-.81 \\
-.75 \\
-.75\end{array}$ & $\begin{array}{r}-0.84 \\
-.86 \\
-.91 \\
-.86 \\
-.81 \\
-.76 \\
-.79\end{array}$ & $\begin{array}{r}-0.83 \\
-.85 \\
-.86 \\
-.86 \\
-.87 \\
-.83 \\
-.81\end{array}$ & $\begin{array}{r}-0.83 \\
-.86 \\
-.89 \\
-.91 \\
-.93 \\
-.84 \\
-.78\end{array}$ & $\begin{array}{r}-0.84 \\
-.87 \\
-.91 \\
-.93 \\
-.86 \\
-.75 \\
-.68\end{array}$ & $\begin{array}{r}-0.86 \\
-.87 \\
-.90 \\
-.89 \\
-.77 \\
-.64 \\
-.60\end{array}$ & $\begin{array}{r}-0.86 \\
-.87 \\
-.88 \\
-.87 \\
-.88 \\
-.85 \\
-.75\end{array}$ \\
\hline
\end{tabular}

FACE A

\begin{tabular}{|c|c|c|c|c|c|c|c|}
\hline $\begin{array}{l}1 \\
{ }^{2} \\
3^{2}\end{array}$ & $\begin{array}{l}0.24 \\
.29 \\
.32 \\
.33 \\
.36\end{array}$ & $\begin{array}{l}0.38 \\
.45 \\
.52 \\
.55 \\
.56\end{array}$ & $\begin{array}{l}0.46 \\
.59 \\
.69 \\
.73 \\
.77\end{array}$ & $\begin{array}{l}0.54 \\
.68 \\
.82 \\
.88 \\
.95\end{array}$ & $\begin{array}{r}0.62 \\
.76 \\
.89 \\
.94 \\
1.00\end{array}$ & $\begin{array}{r}0.62 \\
.73 \\
.81 \\
.83 \\
.86\end{array}$ & $\begin{array}{r}0.54 \\
.62 \\
.64 \\
.66 \\
.66\end{array}$ \\
\hline $\begin{array}{l}6 \\
6 \\
\end{array}$ & $\begin{array}{l}.36 \\
.35 \\
.36 \\
.41 \\
.41\end{array}$ & $\begin{array}{l}.58 \\
.58 \\
.58 \\
.62 \\
.62\end{array}$ & $\begin{array}{l}.79 \\
.80 \\
.79 \\
.82 \\
.82\end{array}$ & $\begin{array}{l}.96 \\
.96 \\
.95 \\
.97 \\
.98\end{array}$ & $\begin{array}{l}1.00 \\
1.00 \\
1.00 \\
1.00 \\
1.00\end{array}$ & $\begin{array}{l}.87 \\
.86 \\
.85 \\
.87 \\
.88\end{array}$ & $\begin{array}{l}.67 \\
.66 \\
.65 \\
.67 \\
.66\end{array}$ \\
\hline
\end{tabular}

FACE C

\begin{tabular}{|c|c|c|c|c|c|c|c|}
\hline 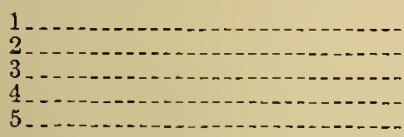 & $\begin{array}{r}-0.57 \\
-.58 \\
-.59 \\
-.62 \\
-.68\end{array}$ & $\begin{array}{r}-0.58 \\
-.59 \\
-.60 \\
-.62 \\
-.68\end{array}$ & $\begin{array}{r}-0.59 \\
-.61 \\
-.62 \\
-.63 \\
-.70\end{array}$ & $\begin{array}{r}-0.62 \\
-.63 \\
-.63 \\
-.65 \\
-.66\end{array}$ & $\begin{array}{r}-0.70 \\
-.70 \\
-.69 \\
-.70 \\
-.70\end{array}$ & $\begin{array}{r}-0.70 \\
-.70 \\
-.70 \\
-.70 \\
-.69\end{array}$ & $\begin{array}{r}-0.70 \\
-.69 \\
-.68 \\
-.69 \\
-.67\end{array}$ \\
\hline 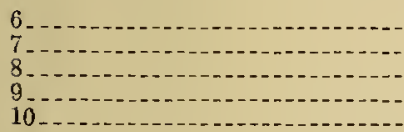 & $\begin{array}{l}-.68 \\
-.61 \\
-.55 \\
-.47 \\
-.41\end{array}$ & $\begin{array}{l}-.66 \\
-.60 \\
-.55 \\
-.48 \\
-.42\end{array}$ & $\begin{array}{l}-.66 \\
-.62 \\
-.57 \\
-.50 \\
-.45\end{array}$ & $\begin{array}{l}-.64 \\
-.60 \\
-.55 \\
-.48 \\
-.41\end{array}$ & $\begin{array}{l}-.67 \\
-.62 \\
-.58 \\
-.49 \\
-.43\end{array}$ & $\begin{array}{l}-.65 \\
-.62 \\
-.57 \\
-.49 \\
-.42\end{array}$ & $\begin{array}{l}-.63 \\
-.61 \\
-.56 \\
-.50 \\
-.44\end{array}$ \\
\hline
\end{tabular}

FACE B

\begin{tabular}{l|r|r|r|r|r|r|r}
\hline & -1.82 & -1.62 & -0.79 & -0.29 & -0.33 & -0.36 & -0.41 \\
\hline 5 & -1.63 & -1.64 & -1.22 & -.22 & -.29 & -.35 & -.42 \\
\hline & -1.47 & -1.52 & -1.51 & -.28 & -.22 & -.32 & -.40 \\
\hline 9 & -1.32 & -1.36 & -1.42 & -.62 & -.17 & -.28 & -.39 \\
\hline & -1.02 & -1.07 & -1.12 & -1.05 & -.81 & -.62 & -.58 \\
\hline
\end{tabular}

FACE D

\begin{tabular}{r|r|r|r|r|r|r|r}
\hline 2 & -0.74 & -0.73 & -0.74 & -0.74 & -0.75 & -0.73 & -0.72 \\
3 & -.73 & -.72 & -.74 & -.73 & -.74 & -.73 & -.72 \\
\hline 5 & -.73 & -.71 & -.73 & -.72 & -.73 & -.70 & -.70 \\
\hline 8 & -.73 & -.71 & -.72 & -.72 & -.73 & -.70 & -.70 \\
\hline 0.69 & -.70 & -.70 & -.71 & -.68 & -.68 \\
\hline & -.69 & -.67 & -.69 & -.67 & -.68 & -.65 & -.65 \\
\hline
\end{tabular}


TABLe 4.-Pressure distribution over model, platform mounting, face $A$ at $120^{\circ}$ [See fig. 14 for designation of faces]

FACE A

\begin{tabular}{|c|c|c|c|c|c|c|c|}
\hline Hole number & $\underset{1}{\text { Column }}$ & $\underset{2}{\text { Column }}$ & $\underset{3}{\text { Column }}$ & $\underset{4}{\text { Column }}$ & $\underset{5}{\text { Column }}$ & $\underset{6}{\text { Column }}$ & $\underset{7}{\text { Column }}$ \\
\hline 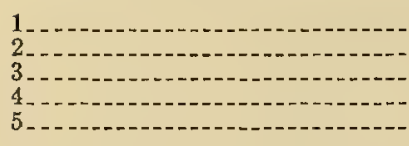 & $\begin{array}{l}0.03 \\
.06 \\
.08 \\
.08 \\
.09\end{array}$ & $\begin{array}{r}0.17 \\
.22 \\
.28 \\
.29 \\
.29\end{array}$ & $\begin{array}{l}0.28 \\
.39 \\
.48 \\
.51 \\
.53\end{array}$ & $\begin{array}{r}0.42 \\
.54 \\
.68 \\
.73 \\
.80\end{array}$ & $\begin{array}{r}0.59 \\
.72 \\
.85 \\
.91 \\
.97\end{array}$ & $\begin{array}{r}0.69 \\
.80 \\
.90 \\
.91 \\
.99\end{array}$ & $\begin{array}{l}0.74 \\
.84 \\
.91 \\
.95 \\
.95\end{array}$ \\
\hline $\begin{array}{l}6 \\
6 \\
8 \\
8\end{array}$ & $\begin{array}{l}.09 \\
.09 \\
.10 \\
.18 \\
.19\end{array}$ & $\begin{array}{l}.31 \\
.31 \\
.32 \\
.37 \\
.60\end{array}$ & $\begin{array}{l}.55 \\
.56 \\
.56 \\
.60 \\
.60\end{array}$ & $\begin{array}{l}.81 \\
.82 \\
.80 \\
.82 \\
.84\end{array}$ & $\begin{array}{r}1.00 \\
1.00 \\
.99 \\
.99 \\
1.00\end{array}$ & $\begin{array}{l}1.00 \\
1.00 \\
1.00 \\
1.00 \\
1.00\end{array}$ & $\begin{array}{l}.96 \\
.95 \\
.95 \\
.95 \\
.97\end{array}$ \\
\hline
\end{tabular}

FACE C

\begin{tabular}{|c|c|c|c|c|c|c|c|}
\hline 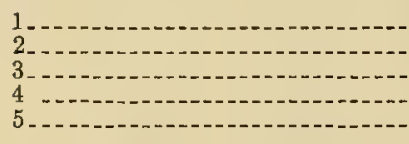 & $\begin{array}{r}-0.56 \\
-.58 \\
-.59 \\
-.62 \\
-.67\end{array}$ & $\begin{array}{r}-0.56 \\
-.58 \\
-.58 \\
-.61 \\
-.66\end{array}$ & $\begin{array}{r}-0.57 \\
-.58 \\
-.60 \\
-.62 \\
-.68\end{array}$ & $\begin{array}{r}-0.56 \\
-.58 \\
-.58 \\
-.61 \\
-.65\end{array}$ & $\begin{array}{r}-0.61 \\
-.61 \\
-.62 \\
-.65 \\
-.71\end{array}$ & $\begin{array}{r}-0.64 \\
-.64 \\
-.65 \\
-.68 \\
-.72\end{array}$ & $\begin{array}{r}-0.61 \\
-.61 \\
-.62 \\
-.63 \\
-.67\end{array}$ \\
\hline $\begin{array}{l}6 \\
6 \\
7 \\
8 \\
9 \\
10\end{array}$ & $\begin{array}{l}-.68 \\
-.64 \\
-.57 \\
-.47 \\
-.41\end{array}$ & $\begin{array}{l}-.65 \\
-.62 \\
-.56 \\
-.48 \\
-.41\end{array}$ & $\begin{array}{l}-.67 \\
-.64 \\
-.59 \\
-.50 \\
-.45\end{array}$ & $\begin{array}{l}-.66 \\
-.62 \\
-.57 \\
-.49 \\
-.42\end{array}$ & $\begin{array}{l}-.70 \\
-.65 \\
-.61 \\
-.52 \\
-.46\end{array}$ & $\begin{array}{l}-.71 \\
-.67 \\
-.62 \\
-.52 \\
-.45\end{array}$ & $\begin{array}{l}-.66 \\
-.62 \\
-.58 \\
-.49 \\
-.42\end{array}$ \\
\hline
\end{tabular}

FACE B

\begin{tabular}{|c|c|c|c|c|c|c|c|}
\hline $\begin{array}{l}1 \\
1 \\
2 \\
3 \\
4 \\
4\end{array}$ & $\begin{array}{r}-0.39 \\
-.33 \\
-.25 \\
-.21 \\
-.17\end{array}$ & $\begin{array}{r}-0.17 \\
-.19 \\
-.18 \\
-.19 \\
-.17\end{array}$ & $\begin{array}{l}+0.06 \\
+.15 \\
+.24 \\
+.27 \\
+.24\end{array}$ & $\begin{array}{r}-0.08 \\
+.01 \\
+.07 \\
+.11 \\
+.13\end{array}$ & $\begin{array}{r}-0.16 \\
-.11 \\
-.07 \\
-.07 \\
-.08\end{array}$ & $\begin{array}{r}-0.22 \\
-.21 \\
-.20 \\
-.20 \\
-.21\end{array}$ & $\begin{array}{l}-0.31 \\
-.31 \\
-.33 \\
-.32 \\
-.34\end{array}$ \\
\hline $\begin{array}{l}6 \\
7 \\
8 \\
9\end{array}$ & $\begin{array}{l}-.15 \\
-.14 \\
-.16 \\
-.12 \\
-.11\end{array}$ & $\begin{array}{l}-.17 \\
-.16 \\
-.17 \\
-.13 \\
-.11\end{array}$ & $\begin{array}{l}+.21 \\
+.20 \\
+.25 \\
+.28 \\
+.28\end{array}$ & $\begin{array}{l}+.13 \\
+.16 \\
+.15 \\
+.16 \\
+.16\end{array}$ & $\begin{array}{l}-.08 \\
-.06 \\
-.07 \\
-.01 \\
-.02\end{array}$ & $\begin{array}{l}-.24 \\
-.22 \\
-.21 \\
-.17 \\
-.17\end{array}$ & $\begin{array}{l}-.37 \\
-.35 \\
-.32 \\
-.23 \\
-.25\end{array}$ \\
\hline
\end{tabular}

FACE D

\begin{tabular}{|c|c|c|c|c|c|c|c|}
\hline $\begin{array}{l}1 \\
1 \\
2 \\
3 \\
4 \\
4\end{array}$ & $\begin{array}{r}-0.67 \\
-.68 \\
-.68 \\
-.70 \\
-.73\end{array}$ & $\begin{array}{r}-0.67 \\
-.67 \\
-.67 \\
-.68 \\
-.72\end{array}$ & $\begin{array}{r}-0.68 \\
-.69 \\
-.68 \\
-.70 \\
-.73\end{array}$ & $\begin{array}{r}-0.67 \\
-.67 \\
-.66 \\
-.67 \\
-.68\end{array}$ & $\begin{array}{r}-0.67 \\
-.67 \\
-.65 \\
-.66 \\
-.68\end{array}$ & $\begin{array}{l}-0.65 \\
-.66 \\
-.64 \\
-.66 \\
-.66\end{array}$ & $\begin{array}{r}-0.64 \\
-.65 \\
-.64 \\
-.65 \\
-.67\end{array}$ \\
\hline $\begin{array}{l}6 \\
6 \\
\\
8 \\
\end{array}$ & $\begin{array}{l}-.73 \\
-.71 \\
-.69 \\
-.62 \\
-.59\end{array}$ & $\begin{array}{l}-.72 \\
-.70 \\
-.66 \\
-.59 \\
-.54\end{array}$ & $\begin{array}{l}-.73 \\
-.70 \\
-.66 \\
-.58 \\
-.53\end{array}$ & $\begin{array}{l}-.68 \\
-.64 \\
-.61 \\
-.52 \\
-.48\end{array}$ & $\begin{array}{r}-.66 \\
-.63 \\
-.58 \\
-.50 \\
-.45\end{array}$ & $\begin{array}{l}-.65 \\
-.62 \\
-.56 \\
-.48 \\
-.43\end{array}$ & $\begin{array}{l}-.66 \\
-.62 \\
-.56 \\
-.47 \\
-.43\end{array}$ \\
\hline
\end{tabular}

TOP

\begin{tabular}{|c|c|c|c|c|c|c|c|}
\hline 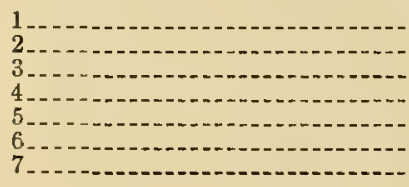 & $\begin{array}{r}-0.82 \\
-.84 \\
-.84 \\
-.83 \\
-.78 \\
-.73 \\
-.71\end{array}$ & $\begin{array}{r}-0.83 \\
-.84 \\
-.85 \\
-.85 \\
-.83 \\
-.73 \\
-.69\end{array}$ & $\begin{array}{r}-0.83 \\
-.85 \\
-.85 \\
-.84 \\
-.73 \\
-.62 \\
-.59\end{array}$ & $\begin{array}{r}-0.83 \\
-.85 \\
-.85 \\
-.79 \\
-.66 \\
-.52 \\
-.50\end{array}$ & $\begin{array}{r}-0.81 \\
-.83 \\
-.84 \\
-.70 \\
-.52 \\
-.54 \\
-.56\end{array}$ & $\begin{array}{r}-0.81 \\
-.82 \\
-1.08 \\
-1.18 \\
-1.05 \\
-.78 \\
-.68\end{array}$ & $\begin{array}{r}-0.79 \\
-.82 \\
-1.10 \\
-1.10 \\
-.90 \\
-.70 \\
-.63\end{array}$ \\
\hline
\end{tabular}


TABLE 5.-Pressure distribution over model, platform mounting, face $A$ at $135^{\circ}$ [See fig. 15 for designation of faces] TOP

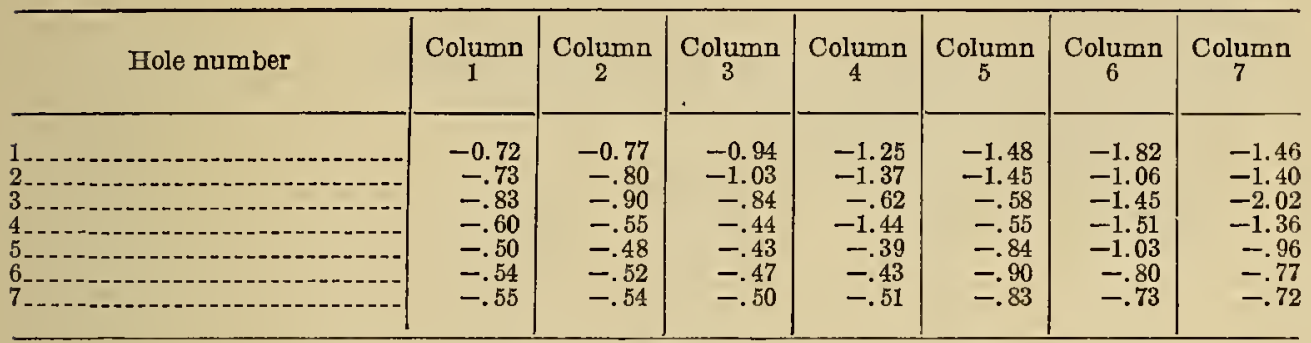

FACE A, OR B IF REVERSED RIGHT TO LEFT

\begin{tabular}{r|r|r|r|r|r|r}
\hline 1 & -0.16 & -0.03 & +0.06 & +0.18 & +0.31 & +0.44 \\
+.57 & +0.54 \\
+.68 \\
3
\end{tabular}

FACE C, OR D IF REVERSED RIGHT TO LEFT

\begin{tabular}{|c|c|c|c|c|c|c|c|}
\hline 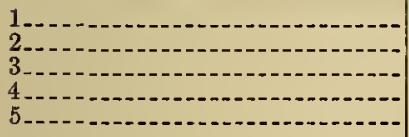 & $\begin{array}{r}-0.61 \\
-.62 \\
-.62 \\
-.64 \\
-.67\end{array}$ & $\begin{array}{r}-0.62 \\
-.62 \\
-.62 \\
-.63 \\
-.67\end{array}$ & $\begin{array}{r}-0.62 \\
-.63 \\
-.64 \\
-.66 \\
-.71\end{array}$ & $\begin{array}{r}-0.60 \\
-.61 \\
-.62 \\
-.65 \\
-.69\end{array}$ & $\begin{array}{r}-0.63 \\
-.64 \\
-.66 \\
-.69 \\
-.73\end{array}$ & $\begin{array}{l}-0.64 \\
-.65 \\
-.68 \\
-.70 \\
-.74\end{array}$ & $\begin{array}{l}-0.64 \\
-.65 \\
-.66 \\
-.69 \\
-.74\end{array}$ \\
\hline $\begin{array}{l}6 \\
6 \\
8 \\
8\end{array}$ & $\begin{array}{l}-.68 \\
-.64 \\
-.57 \\
-.47 \\
-.40\end{array}$ & $\begin{array}{l}-.67 \\
-.63 \\
-.58 \\
-.48 \\
-.42\end{array}$ & $\begin{array}{l}-.70 \\
-.67 \\
-.62 \\
-.50 \\
-.45\end{array}$ & $\begin{array}{l}-.70 \\
-.66 \\
-.62 \\
-.52 \\
-.47\end{array}$ & $\begin{array}{l}-.74 \\
-.72 \\
-.67 \\
-.57 \\
-.50\end{array}$ & $\begin{array}{l}-.75 \\
-.71 \\
-.67 \\
-.58 \\
-.50\end{array}$ & $\begin{array}{r}-.75 \\
-.72 \\
-.66 \\
-.57 \\
-.50\end{array}$ \\
\hline
\end{tabular}




\section{TABLE 6.-Force and moment coefficients for model}

Symbols:

$F=$ total force on any facc or top. Signs refer to axes in Figure 23.

$q=$ velocity pressure.

$h=$ height of prism.

$b=$ width of prism.

$x, y, z=$ coordinates of point of application of force referred to axes of Figure 23.

$M_{\mathrm{v}}=$ vertical moment; that is, moment about $X$ or $Y$ axis of Figure 23 .

$M_{\mathrm{b}}=$ horizontal moment; that is, moment about $Z$ axis of Figure 23 .

$\boldsymbol{M} \boldsymbol{C}_{\mathrm{x}}=$ moment about $X$ axis of Figure 23 .

$M_{\mathrm{y}}=$ moment about $Y$ axis of Figure 23 .

$A, B, C, D$ are designations of faces as shown in Figure 23 .

$A C, B D$ designate values which are the resultants of forces on the opposite faces, $A$ and $C, B$ and $D$. Angles refer to angles of face $A$.

ANGLE $90^{\circ}$ MODEL ON FLOOR

\begin{tabular}{|c|c|c|c|c|c|c|}
\hline Face & $\mathrm{F} / \mathrm{qA}$ & $\mathrm{M}_{\nabla} / \mathrm{qAh}$ & $\mathrm{M}_{\mathrm{b}} / \mathrm{qAb}$ & $x / b$ & $y / b$ & $\mathrm{z} / \mathrm{b}$ \\
\hline $\begin{array}{l}\mathbf{A} \\
\mathbf{B}\end{array}$ & $\begin{array}{c}+0.735 \\
-.889 \\
+.723 \\
+.889 \\
+1.458 \\
0\end{array}$ & $\begin{array}{r}+0.385 \\
+.450 \\
+.388 \\
-.450 \\
+.733 \\
0\end{array}$ & $\begin{array}{l}-0.002 \\
-.009 \\
+.002 \\
+.009 \\
0 \\
0\end{array}$ & +0.011 & $\begin{array}{c}+0.003 \\
-.003 \\
0\end{array}$ & $\begin{array}{r}+0.524 \\
+.506 \\
+.537 \\
+.506 \\
+.530 \\
\end{array}$ \\
\hline
\end{tabular}

ANGLE $105^{\circ}$ MODEL ON FLOOR

\begin{tabular}{|c|c|c|c|c|c|c|}
\hline $\begin{array}{l}\mathrm{A} \\
\mathrm{A} \\
\mathrm{A} \\
\mathrm{B}\end{array}$ & $\begin{array}{r}+0.729 \\
-.815 \\
+.572 \\
+.655 \\
+1.301 \\
-.160\end{array}$ & $\begin{array}{r}-0.377 \\
.410 \\
.310 \\
-.344 \\
.687 \\
.066\end{array}$ & $\begin{array}{r}0.023 \\
.087 \\
-.004 \\
.009 \\
.019 \\
.096\end{array}$ & $\begin{array}{r}-0.107 \\
+.014 \\
-.600\end{array}$ & {$\left[\begin{array}{r}-0.033 \\
+.008 \\
-.015\end{array}\right.$} & $\begin{array}{l}+0.517 \\
+.503 \\
+.542 \\
+.525 \\
+.528 \\
+.412\end{array}$ \\
\hline
\end{tabular}

ANGLE $120^{\circ}$ MODEL ON FLOOR

\begin{tabular}{|c|c|c|c|c|c|c|}
\hline AC ${ }^{\mathrm{A}} \mathrm{B}$ & $\begin{array}{r}+0.626 \\
+.029 \\
+.564 \\
+.618 \\
+1.190 \\
+.589\end{array}$ & $\begin{array}{r}+0.324 \\
+.018 \\
+.302 \\
-.329 \\
+.626 \\
-.311\end{array}$ & $\begin{array}{r}+0.070 \\
-.014 \\
-.006 \\
+.013 \\
+.064 \\
-.001\end{array}$ & $\begin{array}{c}+1.040 \\
+.021 \\
+.015\end{array}$ & \begin{tabular}{c}
-0.111 \\
+.011 \\
-0.054 \\
\hdashline$-10-$
\end{tabular} & $\begin{array}{l}+0.518 \\
+.621 \\
+.536 \\
+.533 \\
+.526 \\
+.528\end{array}$ \\
\hline
\end{tabular}

ANGLE $135^{\circ}$ MODEL ON FLOOR

\begin{tabular}{|c|c|c|c|c|c|c|}
\hline 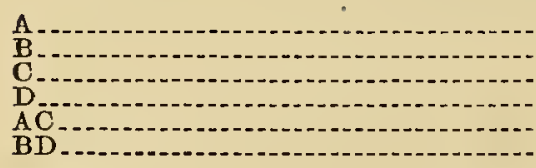 & $\begin{array}{r}+0.398 \\
+.398 \\
+.595 \\
+.595 \\
-.993 \\
+.993\end{array}$ & $\begin{array}{r}+0.203 \\
-.203 \\
+.318 \\
-.318 \\
+.521 \\
-.521\end{array}$ & $\begin{array}{r}+0.080 \\
-.080 \\
+.008 \\
-.008 \\
+.088 \\
-.088\end{array}$ & $\begin{array}{r}-0.201 \\
-.014 \\
-.089\end{array}$ & $\begin{array}{r}-0.201 \\
-.014 \\
-.089\end{array}$ & $\begin{array}{l}+0.510 \\
+.510 \\
+.535 \\
+.535 \\
+.525 \\
+.525\end{array}$ \\
\hline
\end{tabular}

ANGLE $90^{\circ}$ MODEL ON PLATFORM

\begin{tabular}{|c|c|c|c|c|c|c|}
\hline 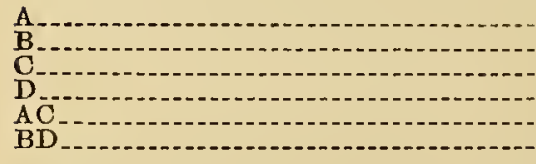 & $\begin{array}{r}+0.798 \\
-.793 \\
+.690 \\
+.793 \\
+1.488 \\
0\end{array}$ & $\begin{array}{l}+0.396 \\
+.408 \\
+.378 \\
-.408 \\
+.774 \\
0\end{array}$ & $\begin{array}{r}-0.002 \\
-.013 \\
-.001 \\
+.013 \\
-.003\end{array}$ & $\begin{array}{r}+0.015 \\
+.015 \\
-\end{array}$ & $\begin{array}{l}+0.003 \\
+.002 \\
+.003 \\
\end{array}$ & $\begin{array}{r}+0.496 \\
+.515 \\
+.544 \\
+.515 \\
+.520\end{array}$ \\
\hline
\end{tabular}


ANGLE $105^{\circ}$ MODEL ON PLATFORM

\begin{tabular}{|c|c|c|c|c|c|c|}
\hline Face & $\mathrm{F} / \mathrm{qA}$ & $\mathrm{M}_{\nabla} / \mathrm{qAb}$ & $\mathrm{M}_{\mathrm{b}} / \mathrm{qAb}$ & $x / b$ & $\mathrm{y} / \mathrm{b}$ & $2 / h$ \\
\hline 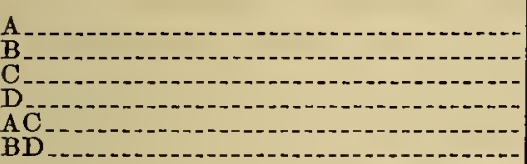 & $\begin{array}{r}+0.779 \\
-.890 \\
+.577 \\
+.643 \\
+1.356 \\
-.247\end{array}$ & $\begin{array}{r}+0.388 \\
+.432 \\
+.314 \\
-.341 \\
+.702 \\
+.091\end{array}$ & $\begin{array}{r}+0.029 \\
+.082 \\
-.002 \\
+.006 \\
+.027 \\
+.088\end{array}$ & $\begin{array}{l}-0.086 \\
+.008 \\
-.035\end{array}$ & $\begin{array}{c}-0.042 \\
+.003 \\
-.021 \\
-0.0-1\end{array}$ & $\begin{array}{r}+0.498 \\
+.485 \\
+.544 \\
+.530 \\
+.518 \\
+.368\end{array}$ \\
\hline
\end{tabular}

ANGLE $120^{\circ}$ MODEL ON PLATFORM

\begin{tabular}{|c|c|c|c|c|c|c|}
\hline $\begin{array}{l}\mathrm{A} \\
\mathrm{A} \\
\mathrm{B}\end{array} \mathrm{B}^{\mathrm{B}} \mathrm{D}$ & $\begin{array}{r}+0.688 \\
+.016 \\
+.579 \\
+.616 \\
+1.267 \\
+.600\end{array}$ & $\begin{array}{r}+0.335 \\
+.016 \\
+.311 \\
+.334 \\
+.646 \\
-.318\end{array}$ & $\begin{array}{r}+0.074 \\
-.021 \\
-.004 \\
+.012 \\
+.070 \\
-.009\end{array}$ & $\begin{array}{c}+0.269 \\
+.018 \\
-.015\end{array}$ & $\begin{array}{r}-0.120 \\
+.006 \\
\hdashline-056 \\
\hdashline-0.0\end{array}$ & $\begin{array}{r}+0.487 \\
+1.000(?) \\
+.537 \\
+.541 \\
+.510 \\
+.530\end{array}$ \\
\hline
\end{tabular}

ANGLE $135^{\circ}$ MODEL ON PLATFORM

\begin{tabular}{|c|c|c|c|c|c|c|}
\hline $\begin{array}{l}\mathrm{A} \\
\mathrm{B} \\
\mathrm{B} \\
\mathrm{B} \\
\mathrm{B}\end{array}$ & $\begin{array}{r}+0.446 \\
+.446 \\
+.612 \\
+.612 \\
+1.058 \\
+1.058\end{array}$ & $\begin{array}{r}0.212 \\
-.212 \\
.328 \\
-.328 \\
.540 \\
-.540\end{array}$ & $\begin{array}{r}0.090 \\
-.090 \\
.008 \\
-.008 \\
.098 \\
-.098\end{array}$ & $\begin{array}{c}-0.239 \\
-.012 \\
-.093\end{array}$ & 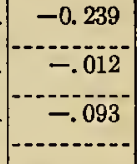 & $\begin{array}{r}+0.475 \\
+.475 \\
+.536 \\
+.536 \\
+.510 \\
+.510\end{array}$ \\
\hline
\end{tabular}

TOP, MODEL ON FLOOR

\begin{tabular}{|c|c|c|c|c|c|}
\hline Angle & $F / q A$ & $\mathbf{M}_{y} / \mathrm{qAb}$ & $\mathrm{M}_{\mathbf{x}} / \mathrm{qAb}$ & I/b & $8 / \mathrm{b}$ \\
\hline 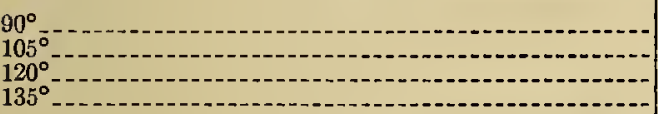 & $\begin{array}{r}+0.901 \\
+.874 \\
+.786 \\
+.809\end{array}$ & $\begin{array}{r}-0.002 \\
+.014 \\
+.022 \\
+.061\end{array}$ & $\begin{array}{r}0.000 \\
+.003 \\
-.010 \\
-.062\end{array}$ & $\begin{array}{r}+0.003 \\
-.017 \\
-.029 \\
-.075\end{array}$ & $\begin{array}{r}0.000 \\
+.003 \\
-.012 \\
-.077\end{array}$ \\
\hline
\end{tabular}

TOP, MODEL ON PLATFORM

\begin{tabular}{|c|c|c|c|c|c|}
\hline $\begin{array}{l}90^{\circ} \\
105^{\circ} \\
120^{\circ} \\
135^{\circ}\end{array}$ & $\begin{array}{r}+0.808 \\
+.844 \\
+.787 \\
+.822\end{array}$ & $\begin{array}{r}-0.001 \\
+.009 \\
+.024 \\
+.060\end{array}$ & $\begin{array}{r}+0.002 \\
.000 \\
-.008 \\
-.062\end{array}$ & $\begin{array}{r}+0.002 \\
-.011 \\
-.029 \\
-.068\end{array}$ & $\begin{array}{r}+0.003 \\
.000 \\
-.011 \\
-.069\end{array}$ \\
\hline
\end{tabular}

\footnotetext{
1 Force very small.
}

TABLE 7.-Typical scale effects. Angle of face A, $135^{\circ}$. Top of model under test [ $p=$ observed pressure difference; $q=$ velocity pressure]

\begin{tabular}{|c|c|}
\hline Speed, miles per hour & $p / q$ \\
\hline Column 4 , row 1: & \multirow{3}{*}{$\begin{array}{l}\text { Model on floor: } \\
-0.96 \\
-0.96 \\
-1.16 \\
-1.15 \\
-1.23\end{array}$} \\
\hline 40.9 & \\
\hline $\begin{array}{l}54.5 \\
68.2\end{array}$ & \\
\hline $\begin{array}{l}\text { Column } 6 \text {, row } 4: \\
27.3 \\
40.9 \\
54.5 \\
68.2\end{array}$ & $\begin{array}{c}\text { Model on platform: } \\
-1.16 \\
-1.57 \\
-1.67 \\
-1.67\end{array}$ \\
\hline $\begin{array}{l}\text { Column } 7, \text { row } 5: \\
27.3 \\
40.9 \\
54.5 \\
68.2\end{array}$ & $\begin{array}{l}\text { Model on platform: } \\
-0.92 . \\
-1.01 \\
-1.02 \\
-1.05\end{array}$ \\
\hline
\end{tabular}

Note.-The values in Tables 2, 3, 4, and 5 are the means of two runs. 


\section{DISCUSSION}

The results of measurements on the platform and on the floor show certain systematic differences in the distribution of pressure. The lower part of the windward face shows in all cases lower pressures for the floor mounting (fig. 6, face A with Table 2). The other faces do not show large differences in the same region, but the following systematic differences occur. For model at $105^{\circ}$ (angle of face A), the decrease in pressure for points in columns 5,6 , and 7 on face B (fig. 11 and Table 3 ) is from 0.05 to 0.20 lower for the floor measure-

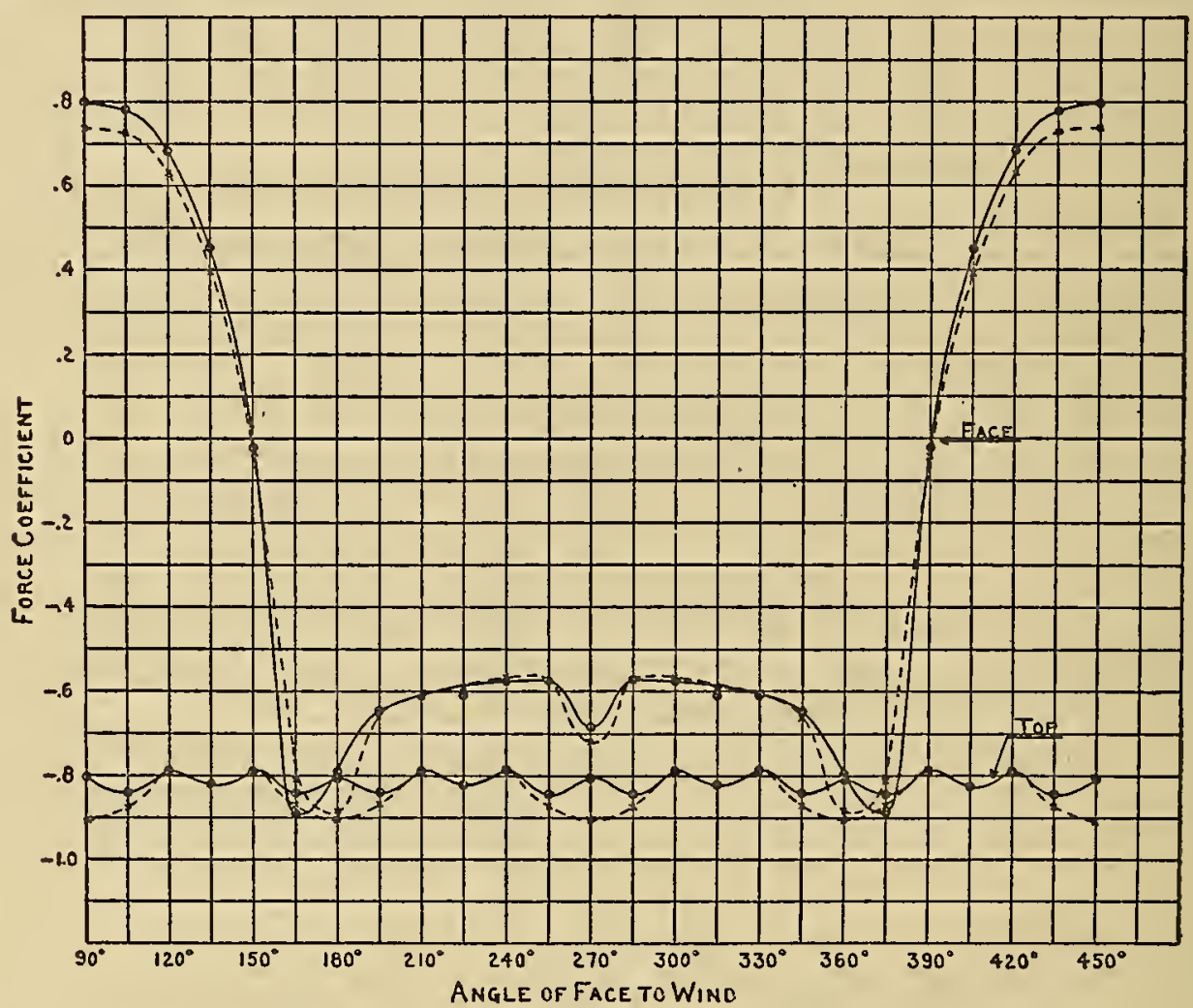

Fig. 18.-Force coefficient for face and top at various angles of face

The force coefficient equals the total force divided by the product of area of face (or top) and velocity pressure. It is the ratio of the average pressure to the velocity pressure. Solid curve refers to platform mounting, dotted curve to floor mounting

ments. At the same angle the decrease in pressure over rows 1,2 , and 3 of the top is higher by 0.05 for the floor measurements (fig. 9 and Table 3). For model at $90^{\circ}$ (angle of face A), the decrease in pressure for face $B$ or $D$ is about 0.05 higher and the decrease over the top is about 0.10 higher for the floor measurements (figs 6,8 , and Table 2).

The general nature of the distributions are closely the same in the two cases and the resultant force and moment curves are nearly identical. The data for the floor mounting will be described in detail. Beginning with Figure 6, face A, normal to the wind we find 
an increase of pressure equal to the velocity pressure near the center of the face, pressures equal to $0.9^{5}$ over a large part of the face, falling off rapidly near the edges to about 0.5 at the outer stations. The average value of $p$ is about 0.74 and is the force coefficient shown in Figure 18. The point of application of the resultant force is near the center of the face, and hence the horizontal moment is small (fig. 19) and the center of moment nearly on the Z-axis of the face (fig. 20).

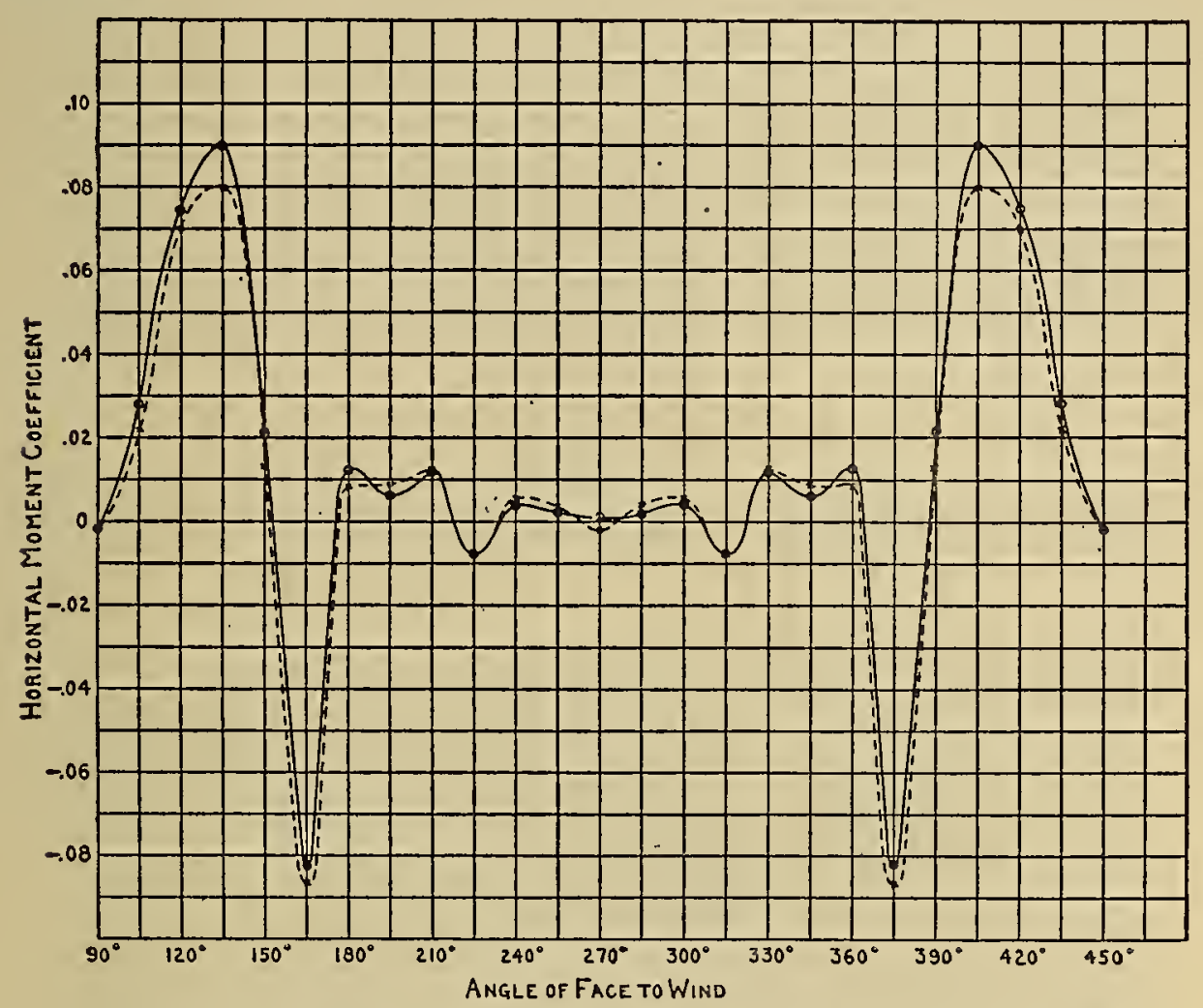

FIG. 19.-Horizontal moment coefficient for face at various angles

The coefficient is equal to the moment about the $Z$-axis of Figure 2 divided by the product of velocity pressure, area of face, and width of face. It is therefore the product of the ratio of the average pressure on the face to the velocity pressure (fig. 18) and the ratio of the horizontal distance of the point of application of the resultant force from the vertical axis of the face to the width of the face (fig. 20). Solid curve refers to platform mounting, dotted curve to floor mounting

Passing next to Figure 10 , face $\mathrm{A}$, at $105^{\circ}$, the distribution is skewed, the value 1 occurring near the edge first struck by the wind; there is a steep gradient to this edge, while toward the rear edge the decrease is at first slow and finally more rapid. The force coefficient is about 0.73 , nearly as large as before, but the point of application has moved to the right (as one views the face) by 0.033 the width of the face and there is a moment tending to bring the face normal to the wind, the moment coefficient being 0.023 .

\footnotetext{
"For ease of discussion "increase of" and "decrease of" will be omitted and replaced by signs and the
} unit of pressure; that is, the velocity pressure, omitted. 
Passing then to Figure 12 , face $A$, at $120^{\circ}$ the same process has continued, the value 1 occurring still nearer the leading edge and values as low as 0.1 occurring near the rear edge. The resultant acts at a distance 0.11 times the width to the right (as one views the face) and the horizontal moment coefficient is 0.070 , the moment tending to turn the face to the original position normal to the wind.

Figure 16 shows face $A$ at $135^{\circ}$. The highest observed pressure is 0.9 near the leading edge, the minimum near the rear edge being -0.1 . The force coefficient has now decreased to 0.39 , the point of application is 0.201 times the width to the right (as one views the

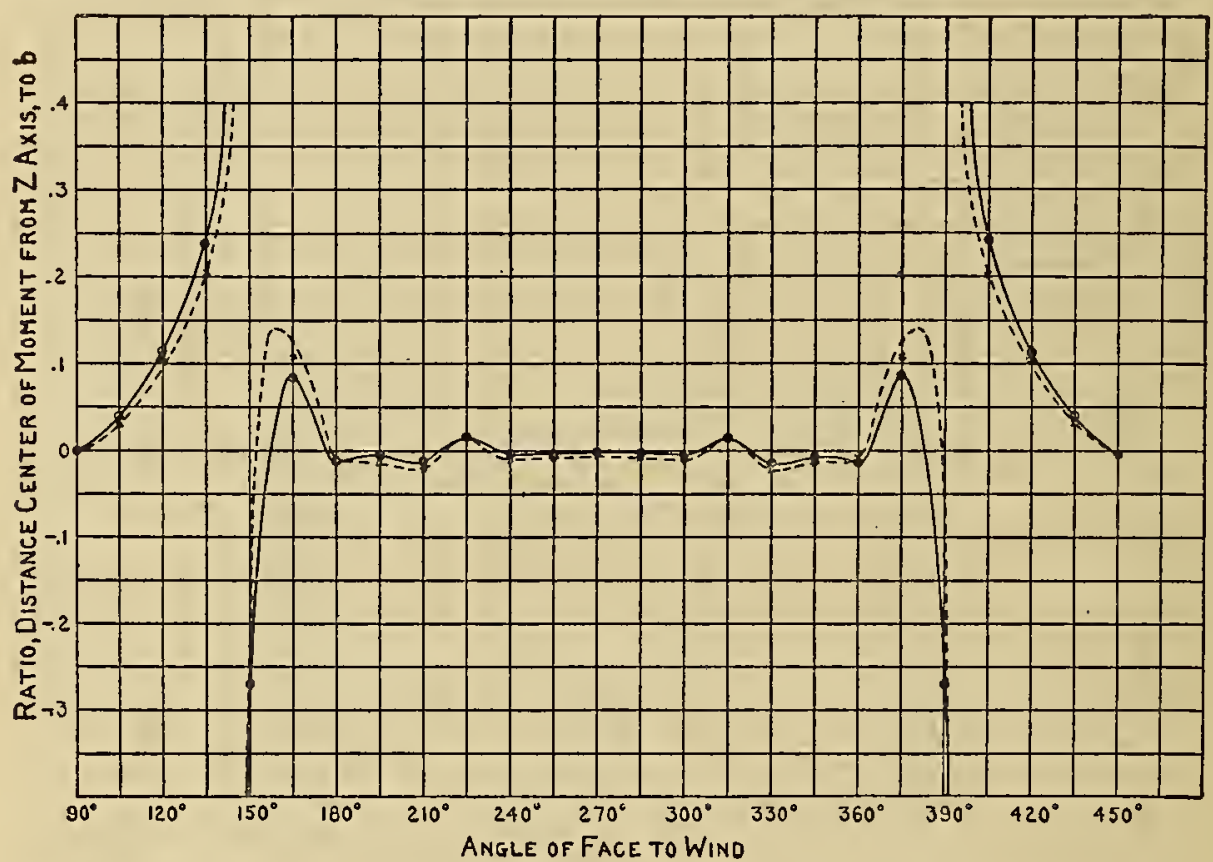

FIG. 20.-Ratio of the horizontal distance of the point of application of the resultant force on the face from the vertical axis of the face to the width of the face; that is, $x / b$, where $x$ is the $x$-coordinate of the center of moment referred to axes of Figure 2 and $b$ is the width

Solid curve refers to platform mounting, dotted curve to floor mounting

face) and the horizontal moment coefficient has reached a maximum of 0.080 .

Face $A$ at $150^{\circ}$ would show a distribution as given in Figure 13 for face $B$, except that it would be reversed from right to left. The pressure near the left edge of the diagram, which is the edge nearest the wind direction, is low, about -0.2 , and the maximum is only 0.39 . Measurements were made every $5^{\circ}$ from 140 to $160^{\circ}$ and the rapid change in pressure followed in more detail. They show the pressure falling off more rapidly at the leading edge than at the center and accordingly reaching negative values while the pressure at the center is still positive. ${ }^{6}$ At $150^{\circ}$ the forcc coefficient is -0.03 ; that is, the

- These data are not shown in the paper. 
pressure distribution is such as nearly to give no resultant force. There is, however, a horizontal moment (couple), the moment coefficient being 0.014 in such a direction as to bring the face normal

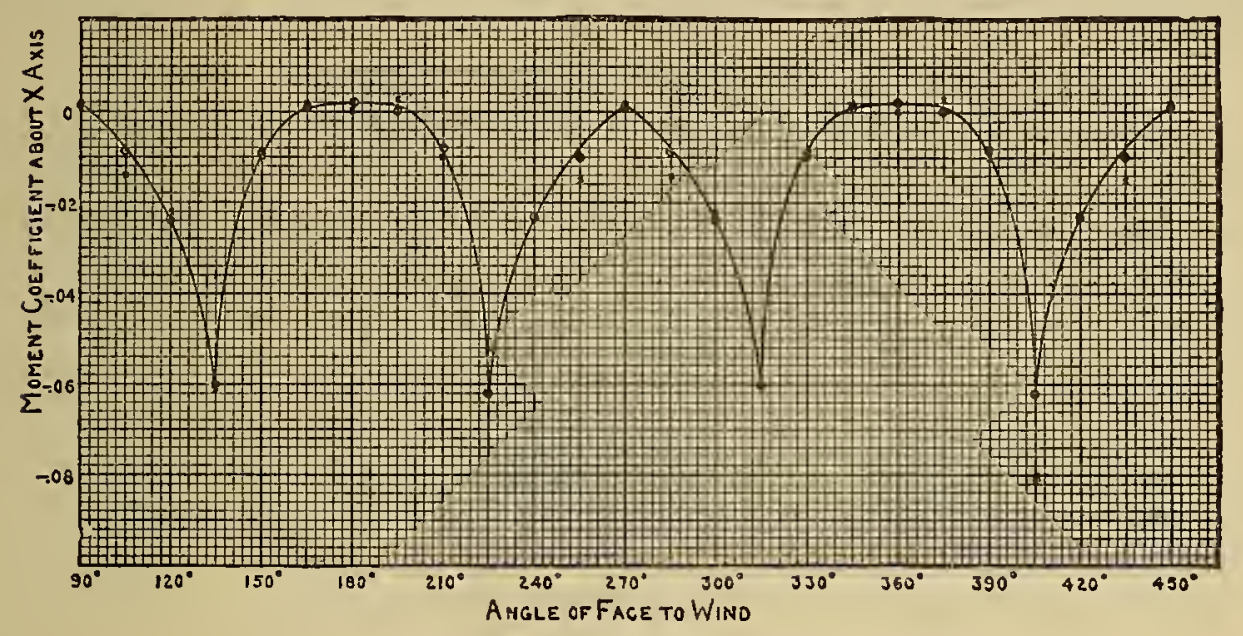

FIG. 21.-Moment coefficient for top at various angles of face

See Figure 2 for axis of moment, the lower edge of the top in the figure being the upper edge of the face from which angles are measured. The caefficient equals the moment about the $X$-axis divided by the product of velocity pressure, area of top, and width of top. Circles refer to platform mounting, crosses to floor mounting

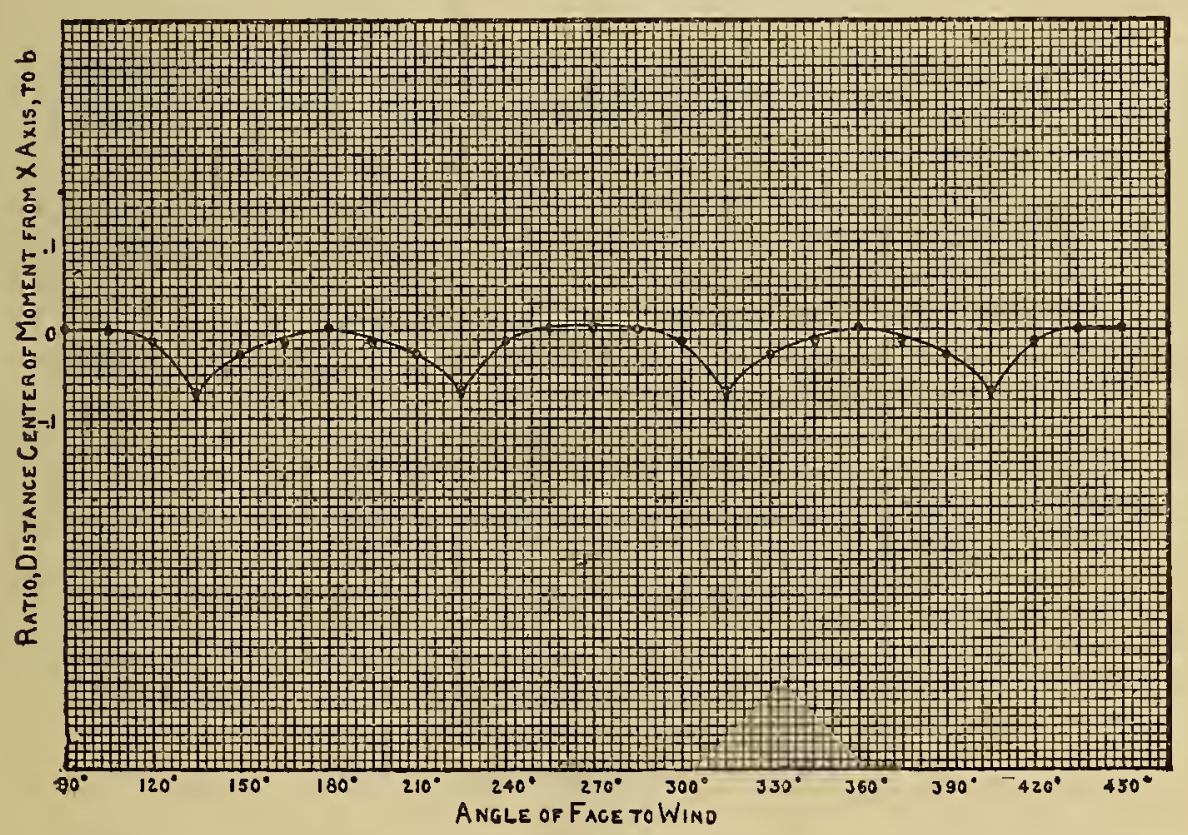

FIG. 22.-Ratio of $y$-coordinate of center of moment on the top to the width of the top, $b$

See Figure 2 for axes. Circles refer to platform mounting, crosses to floor mounting

to the wind. Because of the small force, the center of moment is very far from the center of the face and at about $148^{\circ}$ is at infinity, the resultant force being zero while the moment has a finite value. 
Face $A$ at $165^{\circ}$ would show a distribution as given in Figure 11 for face $B$ reversed from left to right. The pressure has a very large negative value near the leading edge with values decreasing near the rear edge. The force coefficient is -0.82 , the point of application

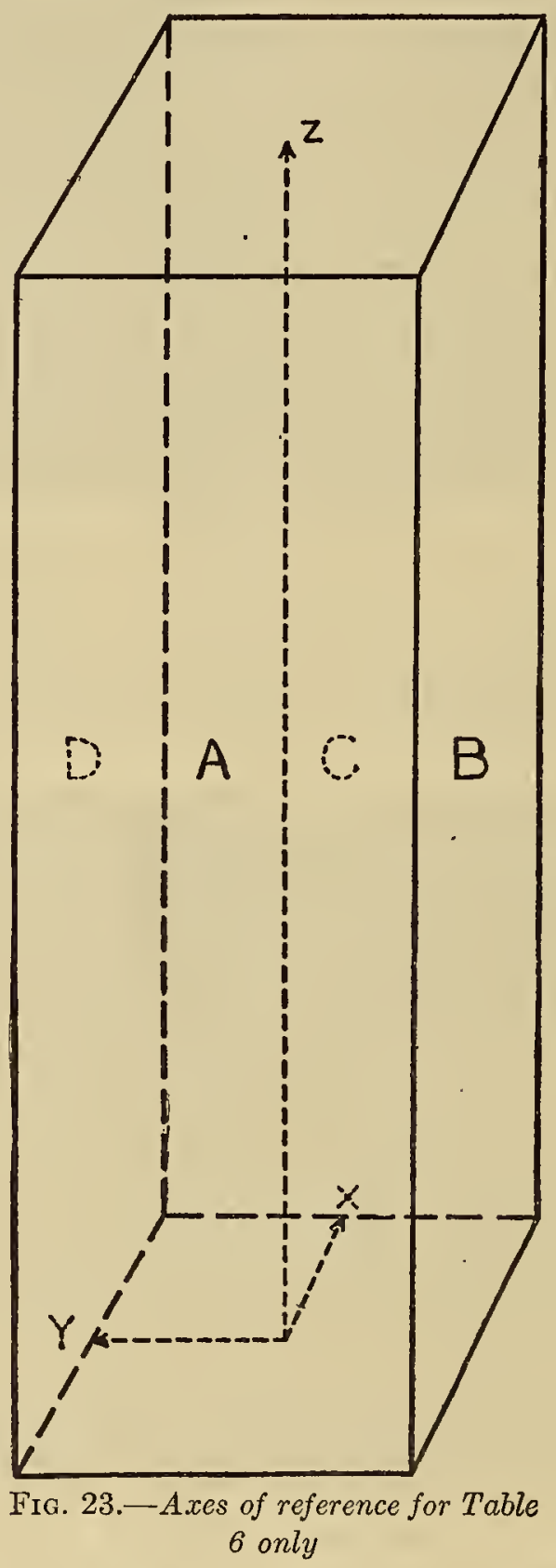

is toward the leading edge and the moment coefficient is -0.087 ; that is, the face tends to turn parallel to the wind direction.

Face $\mathrm{A}$ at $180^{\circ}$ gives the distribution shown in Figure 7 for face $D$. The pressure is nearly uniform over the surface, with an average value of -0.89 . There is a small moment coefficient, namely, 0.009 . 
Figure 11, face D, gives the distribution for an angle of $195^{\circ}$, Figure 13 , face $\mathrm{D}$, the distribution for $210^{\circ}$, and Figure 17 , face D, the distribution for $225^{\circ}$. Figure 12, face C, gives the distribution for $240^{\circ}$, reversed right to left; Figure 9, face C, the distribution for $255^{\circ}$ reversed right to left, and Figure 6 , face $\mathrm{C}$, the distribution for $270^{\circ}$ reversed right to left. All these show nearly constant decrease in pressure and small horizontal moments.

Figure 8 shows the distribution over the top at $90^{\circ}$, a constant decrease in pressure of 0.9 . Figure 9 shows the distribution for $105^{\circ}$, Figure 14 for $120^{\circ}$, and Figure 15 for $135^{\circ}$. Marked peaks are built up in the last two cases, but the average pressure is nearly constant. At $135^{\circ}$ the point of application of the resultant force is 0.07 the width from each of the axes shown in Figure 2.

For the wind in any direction the resultant forces and moments on the complete house may be computed from these curves for the separate faces. Table 6 gives the values referred to the axes shown in Figure 23. At $90^{\circ}$ the average force coefficient is 1.49 for the platform mounting and 1.46 for the floor mounting. From Table 1 it is seen that these values correspond to pressures of 22 and $21.8 \mathrm{lbs} . / \mathrm{ft}^{2}$ at a true speed of 76 miles per hour. This condition $\left(90^{\circ}\right)$ is probably the worst for most types of construction. There is a large force on the front and rear face separately and a large resultant force on the whole structure.

The largest observed horizontal moment on the whole structure occurs at $105^{\circ}$ with a moment coefficient of 0.115 . (Table 6 , sum of $\mathrm{AC}$ and $\mathrm{BD}$ horizontal moments.) At 76 miles per hour true speed for a similar structure 150 feet high and 50 feet wide the moment would be $0.115 \times 14.8 \times 150 \times 50 \times 50=638,250$ pound-feet. The total force at $90^{\circ}$ on such a structure at 76 miles per hour true speed would be 165,000 pounds. In other words, the moment is such as would be produced by an eccentricity of 3.87 feet.

The average decrease in pressure over the top is about 0.84 of the velocity pressure, giving in the above illustration about $12.4 \mathrm{lbs} . / \mathrm{ft}^{2}{ }^{2}$ or a total force of 31,000 pounds tending to lift the roof. Local decreases in pressure are as great as 2.1 (fig. 15) corresponding to $31.1 \mathrm{lbs} . / \mathrm{ft} .{ }^{2}$.

\section{CONCLUSION}

The experiments described in the paper show the distribution of pressure over a square-base right prism of proportions $1: 1: 3$ when resting on a fixed surface with the wind blowing normal to the axis of the prism, but at various angles to the face. The average pressure tending to overturn the building in the most unfavorable case is approximately 1.5 times the velocity pressure, corresponding to a loading of $22 \mathrm{lbs} . / \mathrm{ft}^{2}$ at a true speed of 76 miles per hour. (One 
hundred miles per hour indicated by a standard Weather Bureau Robinson-type anemometer.) Moments about a vertical axis have been computed and it has been shown that in the most unfavorable case the moment is such as would be produced by a displacement of the point of application from the center of the face to one side by an amount equal to 0.077 times the width of the face. The average decrease in pressure on the top is 0.84 of the velocity pressure, corresponding to about $12.4 \mathrm{lbs}$./ft. ${ }^{2}$ at a true speed of 76 miles per hour.

The values of total forces and moments, such as are quoted above, could readily have been obtained by direct measurement and the more important results of the work are the detailed studies of the contributions of the forces on each part of the structure to the total forces and moments. These results can not well be abstracted.

The discussion in this paper applies only to forces resulting from wind pressure and does not take into account lateral forces due to earthquakes or other causes.

Washington, October 16, 1925. 